مجلة كلية التربية الرياضية - جامعة بغداد * المجلا التاسع والعشرون ** العدد الثاني ** لسنة

\title{
تأثير تمرينات بالحبال المطاطية في تطوير بعض القدرات البدنية لناشئي كرة السلة
}

\author{
أ.م.د. قاسم محمد عباس الجنابي
}

\section{$\Delta \mid \leq \mu$}

\section{مستخلص البحث باللغة العربية.}

كرة السلة من الألعاب السريعة التي تحتاج إلى قوة وسرعة وتحمل ورشاقة..... الخ لأجل الانتقال من مكان إلى أخر وكذلك التغطية الدفاعية الناجحة، وتعتمد كل تحركات اللاعب على القوة الانفجارية والقوة مميزة بالسرعة والسرعة الحركية والرشاقة في الاداء لكل أجزاء الجسم وخصوصاً الذراعين والرجلين للاعب، وتجلت أهمية البحث بوضع بيد المدربين والعاملين في مجال التدريب الرياضي وخصوصاً بكرة السلة تمرينات جديدة بالحبال المطاطية (لليد، والذراعين، والرجلين) لرفع مستوى اللاعبين النانشئين في بعض القدرات البدنية وحسب تحركات اللاعبين بتردد الخطوة سريعة لتسمح للاعب بالتحرك بأفضل ما يمكن وإفثال هجوم المنافس وتحويله الى هجوم معاكس وإحراز النقاط، أما المشكلة يتطلب من اللاعب تطوير بعض القرات البدنية من خلال تمرينات خاصة تحاكي طبيعة العمل ولكافة أجزاء الجسم وتحسين اداء العضلات العاملة وتقليل من كبح العضلات المضادة، ومن خلال الاطلاع على العديد من الدراسات والمصادر العلمية السابقة وكذلك تحليل بعض المباريات في كرة السلة وخصوصاً لمنل هذه العينة (الناشئين) وجد الباحث قلة استخدام الأدوات المساعدة لتطوير بعض القدرات البدنية لديهم أرتأى الباحث الخوض في هذه الدراسة من خلال وضع تمرينات كأدوات مساعدة بالحبال المطاطية (لليد، والذراعين، وللرجلين) لتطوير وتحسين بعض القدرات البدنية لاى ناشئي كرة السلة، وكان الغرض من الدراسة هو إعداد تمرينات جديدة بالحبال المطاطية (لليد، والذراعين، وللرجلين) لتطوير وتحسين بعض القدرات البدنية لدى ناشئي كرة السلة، والتعرف على تأثنير هذه الوسائل التدريبية على هذه العينة، ومعرفة الأفضلية بين هذه الوسائل التدريبية باستعمال (الحبال المطاطية)، وحدد الباحث مجتمع البحث وهم

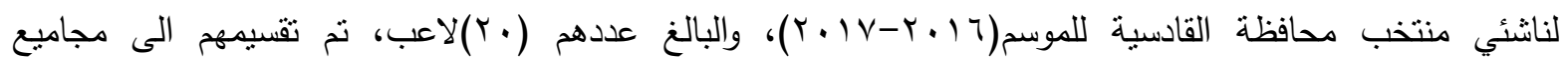
مجموعات (بتجريبيات، وضابطة)، اذ كانت كل مجموعة مكونة من (0) لاعبين، واستخدم الباحث المنهج التجريبي بأسلوب المجموعات المتكافئة وتم التجانس في المجموعات ككل والتكافؤ بينها وبعد الحصول على بيانات الاختبارات نم إجراء المعالجات الإحصائية لها ثم نم عرضها على شكل جداول ومن ثم تحليلها ومناقشتها واستتتج الباحث بعض الاستتناجات واهمها بأن تمرينات بالحبال المطاطية لها أثز إيجابي في تطوير بعض القدرات البدنية لدى ناشئي كرة السلة ووضع التوصيات وحسب ما تم التوصل اليه من الاستتناجات. 


\section{Abstract. \\ The Effect of Rubber-Band Exercises On The Development Of Some Physical Abilities of Basketball Players}

Basketball is one of the fastest games that needs strength, speed, endurance, agility, etc. for moving from one place to another, as well as successful defense coverage. All moves of the player depend on the explosive power, power defined by speed, motor speed, and agility in performance for all parts of the body especially the arms and legs. The importance of research lies in using rubber ropes (for the hands, arms, and legs) to improve young players' physical abilities. The problem of the research lies in the lack of teaching aids for young players that improve their physical abilities. The research aimed at designing exercises using rubber bands for hand, arm and leg to develop and improve young basketball players as well as identifying the effect of these exercises on the subjects. The researcher used the experimental method. The subjects were (20) young basketball players divided into three experimental and one controlling group. The data was collected and treated using proper statistical operations to conclude that rubber band exercises have a positive effect on developing the physical abilities of young basketball players. Finally the researcher recommended using these exercises for developing the physical abilities of young basketball players.

$$
\begin{aligned}
& \text { 1- - المبحث الأول: التعريف بالبحث. } \\
& \text { 1- المقدمة وأهمية البحث: } \\
& \text { تعد كرة السلة واحدة من الالعاب الجماعية التي تتنتمل على العديد من المهارات الاساسية المتتوعة والتي } \\
& \text { تتطلب درجة عالية من الدقة والاتقان لتحقيق الهدف المرجو من ادائها وتطوير القدرات البدنية وكذلك الجوانب المهارية } \\
& \text { وبالتالي كلما وجدنا ما يساعد المتدرب والمتعلم في تحريك أكثر جزء من الجسم بانسيابية عالية سيسهم في رفع مستواه } \\
& \text { البدني. } \\
& \text { ونظراً لما تتمتع به لعبة كرة السلة من شعبية كبيرة على مستوى بلدان العالم بما يتسم بها لاعبها من } \\
& \text { صفات عند أدائه داخل الملعب للوصول إلى المستوى المطلوب من خلال توزيع المجهود البدني الصحيح، وكرة السلة } \\
& \text { من الألعاب السريعة التي تحتاج إلى قوة وسرعة وتحمل ورشاقة..... الخ لأجل الانتقال والتحرك من مكان إلى أخر } \\
& \text { وكذلك التغطية الدفاعية الناجحة. }
\end{aligned}
$$


مجلة كلية التربية الرياضية - جامعة بغداد * المجلا التاسع والعشرون * العدد الثاني * لسنة

وتعتمد التحركات للاعبين على القوة الانفجارية والقوة مميزة بالسرعة والسرعة الحركية والرشاقة في الاداء

لكل أجزاء الجسم وخصوصاً الذراعين والرجلين للاعب.

وتجلت أهية البحث بوضع بيد المدربين والعاملين في مجال التدريب الرياضي وخصوصاً بكرة السلة

تمرينات جديدة بالحبال المطاطية (لليد، والذراعين، والرجلين) لرفع مستوى اللاعبين الناشئين في بعض القدرات البدنية

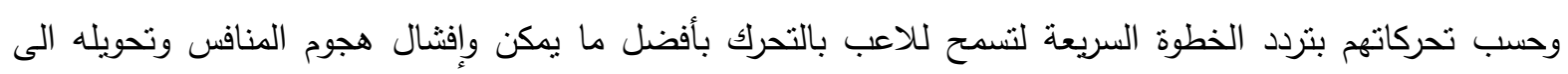

هجوم معاكس وإحراز النقاط.

r-1

لعبة كرة السلة من الألعاب التي تحتاج الى قدرات بدنية فضلاً عن الجوانب الحركية في كافة التحركات في الملع، وأن التدرب عليها ونطويرها يحتاج الى العديد من الصفات كـ (القوة، السرعة، التحمل، المرونة، الرشاقة....الخ) وجعلها قدرات من خلال التداخل بينها والذي من شأنها رفع مستوى الأداء لاى اللاعبين الناشئين في كرة السلة، وأن التحرك بخطوات سريعة وتردد مناسب وحسب وجود المهاجمين وتغطية المناطق بسرعة مناسبة وحسب الخطط الموضوعة من المنافس ومحاولاته المستمرة لاختراق الخطوط الدفاعية المرسومة من قبل المدرب لها أهمية كبيرة متأنية من مجمل من العمليات التي منها الجوانب البدنية وترجمتها من خلال هذه المهارات نحو إفثال هجوم المنافس وتشكيل هجوم مضاد نحو هدف المناف، وهذه يتطلب من اللاعب تطوير بعض القدرات البدنية من خلال تمرينات خاصة تحاكي طبيعة العمل ولكافة أجزاء الجسم وتحسين اداء العضلات العاملة وتقليل من كبح العضلات المضادة، ومن خلال الاطلاع على العديد من الدراسات والمصادر العلمية السابقة وكذلك تحليل بعض المباريات في كرة السلة وخصوصاً لمثل هذه العينة (الناشئين) وجد الباحث قلة استخدام الأدوات المساعدة لنطوير بعض القدرات البدنية لديهم، لذا أرتأى الباحث الخوض في هذه الدراسة من خلال وضع تمرينات جديدة كأدوات مساعدة بالحبال المطاطية (لليد، والذراعين، وللرجلين) لتطوير وتحسين بعض القدرات البدنية لدى ناشئي كرة السلة.

r- r r أهداف البحث:

ا. إعداد تمرينات بالحبال المطاطية (لليد، والذراعين، وللرجلين) لنطوبر وتحسين بعض القدرات البدنية لدى ناثشئي

كرة السلة.

r. التعرف على نأثثر هذه الأدوات المساعدة في نطوير بعض القدرات البدنية لدى ناشئي كرة السلة. r. التعرف على الأفضلية بين هذه الأدوات المساعدة باستعمال (الحبال المطاطية) والفروق بين المجموعات.

|

ا ـ هناك تأثثير إيجابي للأدوات المساعدة (الحبال المطاطية) في تطوير بعض القدرات البدنية لدى ناشئي كرة السلة. 
مجلة كلية التربية الرياضية - جامعة بغداد * المجلد التاسع والعثرون * العدد الثاني ** لسنة

r. . هنالك فروق ذات دلالة إحصائية بين المجموعات للأدوات المساعدة (الحبال المطاطية) في تطوير بعض القدرات البدنية لدى ناشئي كرة السلة.

\section{r - المبحث الثاني: منهج البحث وإجراعاته الميدانية. r - 1 1 مجتمع وعينة البحث:}

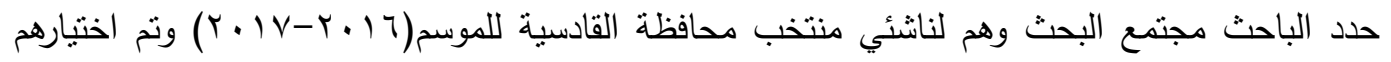

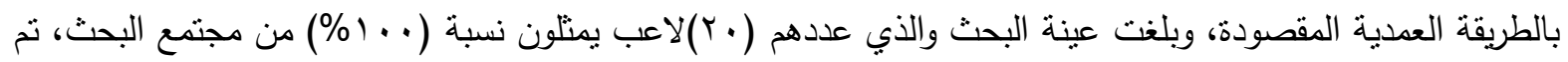
تقسيمهم الى مجاميع مجموعات (بتجريبيات، وضابطة)، اذ كانت كل مجموعة مكونة من (0) لاعبين، المجموعة الاولى (تجريبية الأولى) اذ تقوم بأداء تمرينات بالأداة المساعدة بربط الحبال على الرجلين فقط، والمجموعة الثانية (التجريبية الثانية اذ تقوم بأداء تمرينات بالأداة المساعدة بربط الحبال على اليد والذراعين فقط، والدجموعة الثالثة (التجريبية الثالثة اذ نقوم بأداء تمرينات بالأداة المساعدة بربط الحبال على اليد والذراعين والرجلين، والمجموعة الرابعة (الضابطة) تقوم بأداء تمرينات المدرب فقط، وتم إجراء التجانس بين المجموعات ككل والتكافؤ بين المجموعات في متغيرات (الطول، الوزن، العمر، الاختبارات قيد الدراسة).

جدول (1) (1) (1)

يبين التجانس لأفراد عينة البحث بين المجموعات

\begin{tabular}{|c|c|c|c|c|c|}
\hline الاختلاف معامل & $\varepsilon^{ \pm}$ & 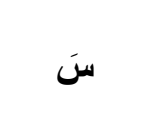 & وحدة & 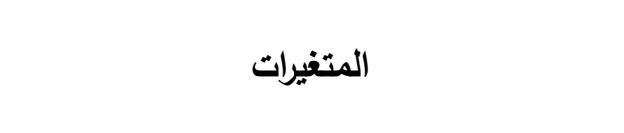 & $ت$ \\
\hline$\% 0,0 \wedge 9$ & $q, r \cdot r$ & $177, \varepsilon Y 7$ & سم & 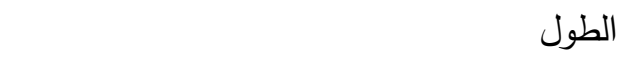 & -1 \\
\hline$\%) r, 79 \vee$ & $7,1<9$ & $\varepsilon \wedge, r \vee 1$ & كغ & 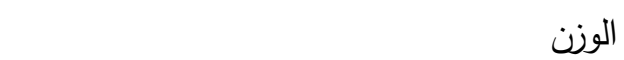 & $-r$ \\
\hline$\% \backslash \vee, r r$. & $0,1 \vee 9 \leq$ & rT, ¿\&Y & \multirow{2}{*}{ كغم } & قوة القبضة (يمين) & \multirow{2}{*}{ 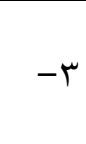 } \\
\hline$\%) \vee, \wedge \uparrow \wedge$ & $7,1 \wedge r$ & $r \varepsilon, 091$ & & قوة القبضة (يسار) & \\
\hline$\% \backslash \leq, \vee 0$. & 1,202 & 8,149 & \multirow{2}{*}{ 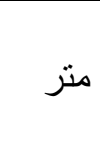 } & القوة الانفجارية للذراع(يمين) (كرة طبية؟ كغم) & $-\varepsilon$ \\
\hline$\% \backslash 7, \wedge r r$ & 1,312 & 7,799 & & القوة الانفجارية للذراع (بسار ) (كرة طبيةس كغم) & -0 \\
\hline$\%$ Y, $9 \leq \varepsilon$ & 4,113 & 18,743 & يمين & \multirow{2}{*}{ اختبار قوة العضلات المادة للذراع (كغم) } & \multirow{2}{*}{-7} \\
\hline$\%) \vee, \wedge \wedge q$ & 3,151 & 17,614 & يسار & & \\
\hline \%וr, r ג & $7, Y$ T & $\varepsilon v, 1.0$ & سم & القفز العمودي من الثبات & $-v$ \\
\hline$\% \backslash 1,0 Y_{1}$ & $\cdot, V \pi r$ & $7,7) \leq$ & 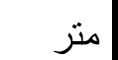 & القوة المميزة بالسرعة للرجلين & $-\Lambda$ \\
\hline$\% \curlyvee, \leqslant 0$. & $\cdot, 9 \wedge r$ & 10, & ثانية & 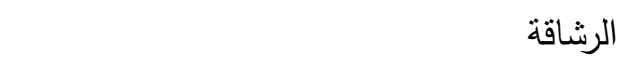 & -9 \\
\hline \%У,rru &., $1 \vee \wedge$ & $r, \varepsilon r \wedge$ & ثانية & الاستجابة الحركية الانتقائية & -1 \\
\hline
\end{tabular}


مجلة كلية التربية الرياضية - جامعة بغداد * المجلا التاسع والعشرون ** العدد الثاني ** لسنة

وكما مبين في الجدول (1) إن قيم معامل الاختلاف قد انحصرت تحت (·r\%) وهذا يدل على تجانس

العينة في المجموعة الواحدة " فكلما قرب معامل الاختلاف من (1\%) يعد تجانساً عالياً وإذا زاد عن(·r\%) يعني أن

العينة غير متجانسة "(161:14).

جدول (r)

يبين التكافؤ بين المجموعات لأفراد عينة البحث

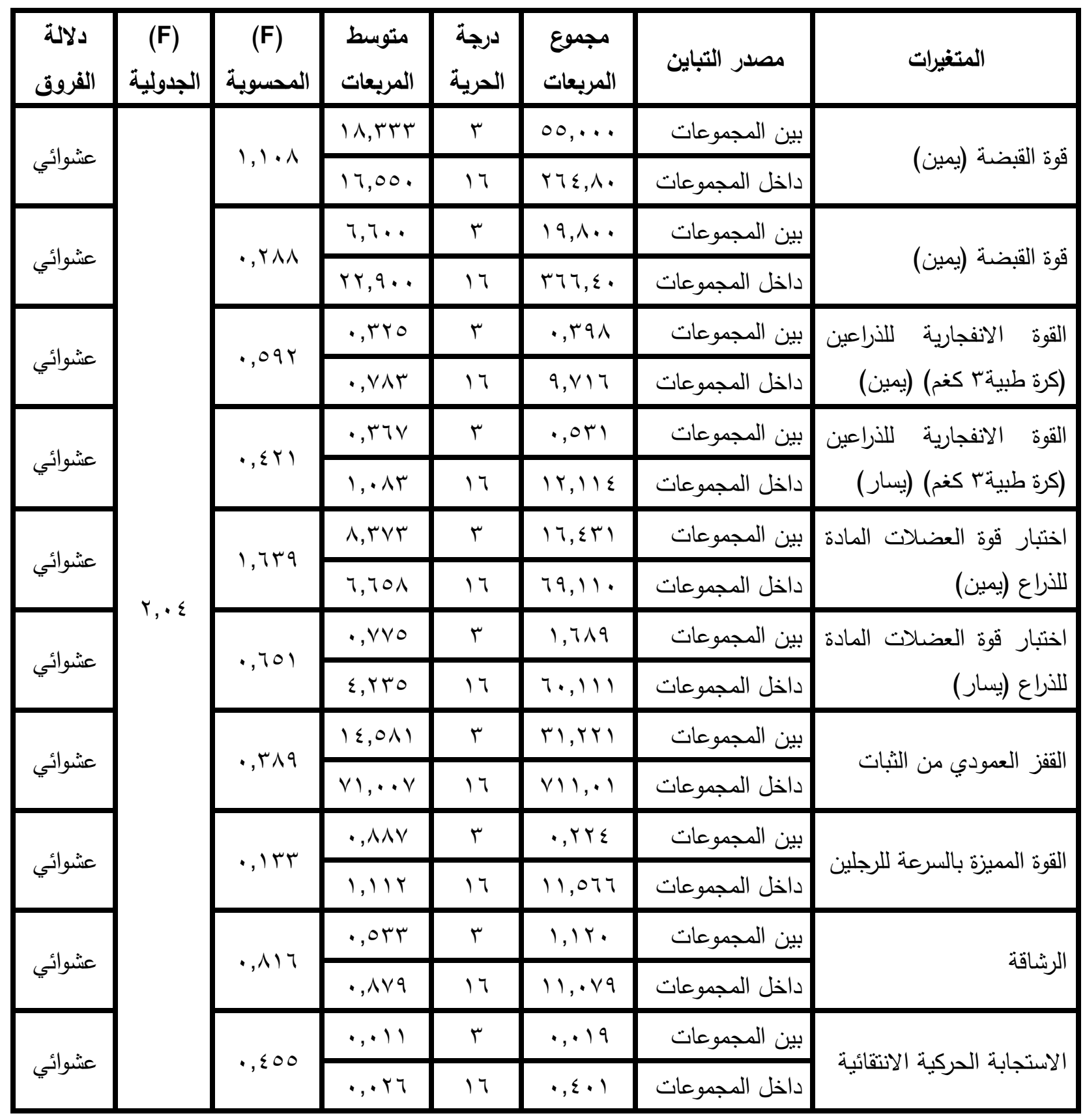

* عند مستوى دلالة(0., • •) ودرجة حرية (r-7 (1). 
مجلة كلية التربية الرياضية - جامعة بغداد * المجلد التاسع والعثرون * العدد الثاني ** لسنة

r-r

استخدم الباحث المنهج التجريبي بأسلوب المجموعات المتكافئة لملاعمته لطبيعة الدراسة، حيث كانت هناك

أربع مجاميع ثلاثة منها تستخدم أدوات مساعدة (الحبال المطاطية) وأخرى تستخدم المنهاج المعد من قبل المدرب، نم مراعاة العمر لهذه الفئة العمرية قام الباحث بإجراء التجانس للجموعات ككل ومن ثم توزيع العينة بينها عشوائياً بعد ثبوت التجانس بينها بمتغيرات الدراسة وبعدها إجراء التكافؤ بين المجموعات حتى تكون بخط شروع واحد وتكون الفروق اذا ظهرت للأدوات المساعدة باستعمال (الحبال المطاطية) وليس لأفراد العينة والاختلاف بينها، وعند جمع البيانات من الاختبارات القبلية والبعدية وإجراء العمليات الإحصائية عليها نظهر لنا جداول ينم عرضها وتحليلها ومناقثتها وفق ما ظهر من نتائج ووضع الاستتناجات والتوصيات لها، تمت اختيار الاختبارات بعد الاطلاع على الدراسات السابقة والمصادر العلمية وهي شبيهه في أغلبها الى طبيعة العمل لكرة السلة.

r-r الوسائل والأدوات والأجهزة المستخدمة في البحث: r-r

$$
\begin{aligned}
& \text { المصادر والمراجع العربية. } \\
& \text { الملاحظة والتجريب. } \\
& \text { الاختبارات والقياس. } \\
& \text { استمارة جمع وتفريغ البيانات. }
\end{aligned}
$$

r-r-r

$$
\text { شريط قياس (سنتمتري، كتان). }
$$

جهاز دايناموميتر لقياس العضلات المادة للذراع.

• •

جهاز المولتجم.

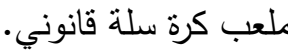

كرة سلة عدد (0).

كرة طبية زنة (سكغم) عدد/r.

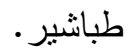

ساعات توقيت عدد(r).

مسحوق الاسمنت الأبيض.

قطعة قماش لمسح العلامات. 
مجلة كلية التربية الرياضية - جامعة بغداد * المجلا التاسع والعشرون * العدد الثاني * لسنة

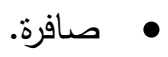

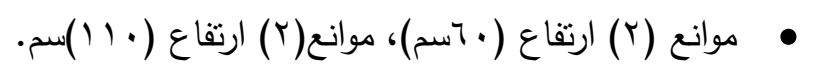

$$
\begin{aligned}
& \text { • شواخص(0). } \\
& \text { • بساط جمناستك. } \\
& \text { • لوحة بداية الكترونية لحساب الزمن من البدء والنهاية. } \\
& \text { • حبال مطاطية أمريكية الصنع بطول (، (سم) عدد/0 . } \\
& \text { r - إجراءات البحث الميدانية: } \\
& \text { r- - - الاختبارات المستخدمة في البحث: } \\
& \text { r- - - - 1 اختبار قوة القبضة (يمين ويسار): (366:6) } \\
& \text { • الهُف من الاختبار : قياس قوة القبضة (اليمين واليسار ). }
\end{aligned}
$$

• الأدوات المستخدمة: (جهاز دانيوميتز Grip manometer)

• تعليمات الأداء: يمسك المصارع بجهاز مانيوميتر بقبضتها اليمنى وتكون الذراع مددودة من دون وجود أي ثثي

$$
\text { في مفصل المرفق وتبتعد قليلا عن الجسم. }
$$

• حساب الدرجات: يقوم الدصارع بالضغط بقبضة اليد على الدالنيوميتر لـحاولة إخراج أقصى قوة ممكنة ويعطى

$$
\text { لكل مصارع ثلاث محاولات تؤخذ افضل محاولة. }
$$

\section{r - - - - اختبار القدرة العضلية باستخدام الكرة الطبية (ب كفم): (94:8)}

الهذف من الاختبار: قياس القدرة العضلية لمنطقة الذراع والكتف.

$$
\text { • • الأدوات اللازمة: كرات طبية وشريط قياس. }
$$

• الإجراءات: يقف المختبر خلف الخط وحاملاً الكرة الطبية بإحدى يديه، حيث يقوم برمي الكرة الطبية للحصول

$$
\text { على أبعد مسافة والثنكل ( (1) يوضح ذلك. }
$$

• حساب الارجات: يحسب للمختبر الواحد ثلاث محاولات منتالية والاداء الخاطئ يحتسب محاولة وتحتسب

للمختبر نتيجة أحسن محاولة من المحاولات. 
مجلة كلية التربية الرياضية ـ جامعة بغداد * المجلد التاسع والعثرون * العدد الثاني * لسنة

$$
\checkmark \text {. } 1
$$

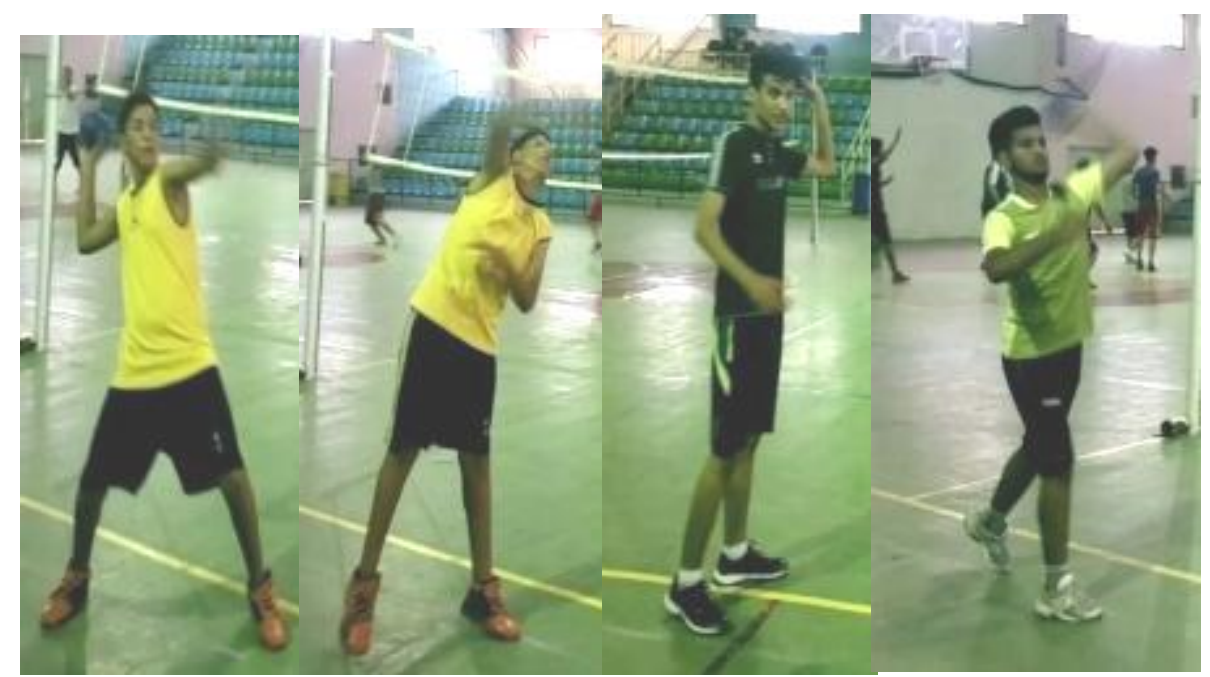

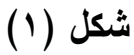

يوضح اختبار رمي الكرة الطبية (يمين ويسار)

r - - - - ب اختبار القوة المميزة بالسرعة ثلاث حجلات برجل اليمين واليسار: (87:9)

• الههف من الاختبار : قياس القوة المميزة بالسرعة للرجل اليمين واليسار •

$$
\text { • • الأدوات: شريط قياس، صافرة. }
$$

• مواصفات الأداء: بقف المختبر خلف خط البداية على أحد رجليه ويقوم بثلاث حجلات بنفس الرجل الى أبعد

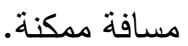

$$
\text { • الثروط: يجب الدفع بالقدم من وضع الثبات، سرعة في الأداء. }
$$

• التسجيل: تعطى محاولتين لكل رجل على حدة وتؤخذ أحسن محاولة، وتقاس بشريط القياس لأقرب سنتيمتر .

r - - - - ع اختبار قوة العضلات المادة للاراع (اليمين واليسار): (207:8)

$$
\text { • الهدف من الاختبار: قياس القوة للعضلات المادة للذراع. }
$$

• • الأدوات اللازمة: جهاز ديناموميتر ، سلك معدني، جهاز المولتجم.

• الإجراءات: يقف المختبر على قاعدة جهاز الديناموميتز دمسك بيده جهاز الديناموميتر بواسطة المقبض ادر الحديدي المربوط بجهاز المولتجم بواسطة السلك البلاستيكي والتي يمكن التحكم بطوله حسب طول اللاعب، وعند إعطاء إثنارة البدء يقوم المختبر بالضغط للأسفل بيد واحدة مع مراعاة ثبات الرجلين والجذع أثناء عملية السحب بحيث تكون القوة المنتجة بواسطة ذراع واحدة فقط، وتعاد المحاولة على الذراع الأخرى وكما مبين في

$$
\text { الثكل (r). }
$$

• حساب الارجات: تعطى لكل مختبر محاولتين لكل ذراع وتحسب افضل محاولة له. 
مجلة كلية التربية الرياضية - جامعة بغداد * المجلد التاسع والعشرون ** العدد الثاني * لسنة

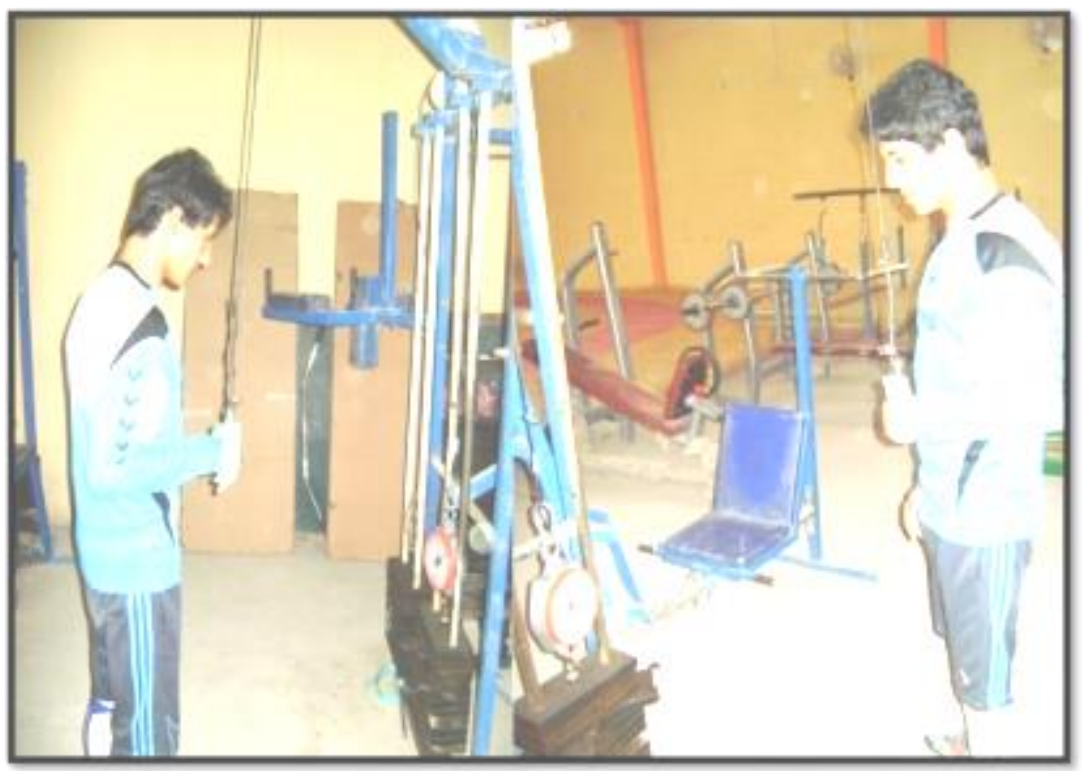

شكل (r)

يوضح قياس القوة القصوى لعضلات الذراع المادة للعضد اليمين واليسار

r - - - -ه اختبار القفز العمودي من الثبات لسارجنت: (45:17)

• الهذف من الاختبار : قياس القوة الانفجارية لعضلات الرجلين.

• الأدوات: حائط أملس مدرج من (101- (1... سم، مسحوق الاسمنت الأبيض، قطعة قماش لمسح العلامات.

•مواصفات الأداء: يغمس المُختَّرِ أصابع اليد المميزة في مسحوق الاسمنت الأبيض، ثم يقف بحيث تكون ذراعه

الممدودة عالياً جانباً لحائط، يقوم المختبر برفع الذراع المميزة عالياً على كاملاً امتدادها لعمل علامة بالأصابع على الحائط، ويجب ملاحظة عدم رفع الكعبين من الأرض، يسجل الرقم الذي تموضع العلامة إمامة، من وضع الوقوف يمرجح المختبر الذراعين أماماً عالياً ثم أماماً خلفاً مثثي الركبتين نصفاً ثم مرجنتهما لإمام عالياً

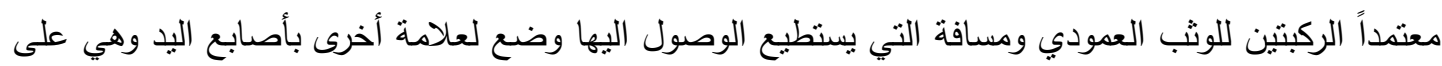
كامل امتدادها. التوجيهات: عند أداء العلامة الأول يجب عدم رفع العقبين من على الأرض كما يجب عدم رفع كتف الذراع المميز عن مستوى الكتف الأخرى أثثاء وضع العلامة اذ يجب ان يكون الكتف على استقامة واحدة يؤدي المختبر مرجحتين عند التحضير للققز •

الشروط: لكل مُختَّبر ثلاث محاولات ينم جمع الدرجات للمحاولات الثناثة واستخراج المتوسط الحسابي لها. التسجيل: تعد المسافة بين العلامة الأولى والعلامة الثانية مقدار ما بتمتع بهِ المُخنَّبر مِن القدرة الانفجارية للاجلين مقاساً بالسنتيمتر . 
مجلة كلية التربية الرياضية - جامعة بغداد * المجلد التاسع والعثرون * العدد الثاني ** لسنة

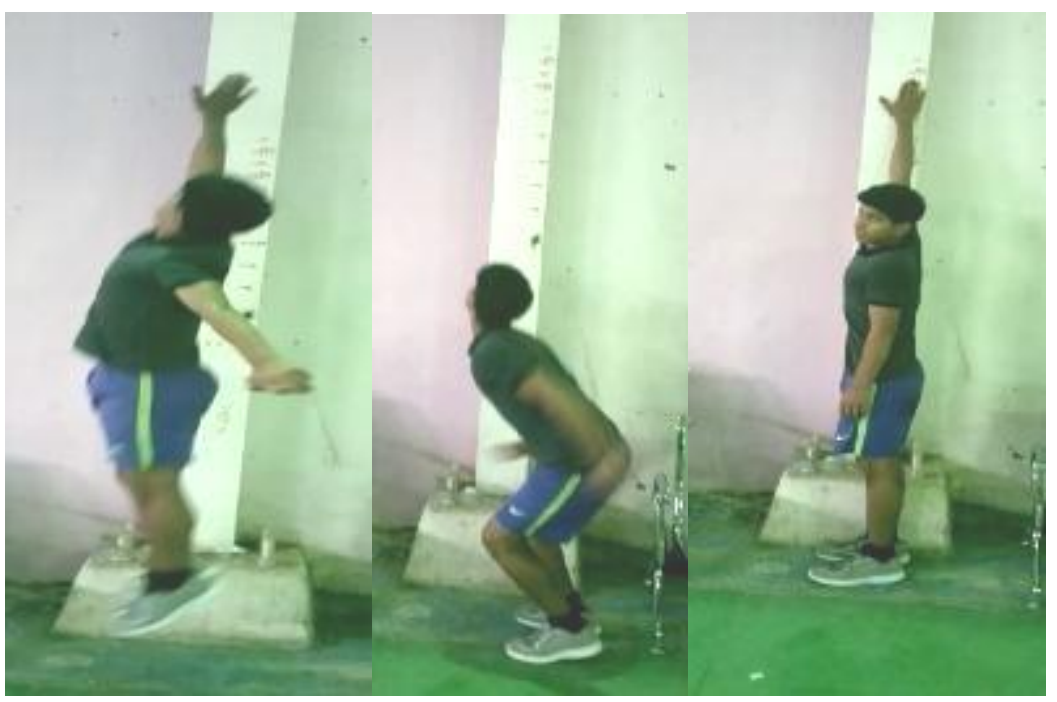

شكل (ب)

يوضح اختبار القفز من الثبات

(265:8) (

الهلف من الاختبار: قياس الرشاقة.

• الأدوات: موانع (Y) ارتفاع (• آسم)، موانع (Y) ارتفاع (• (1)(سم، شواخص (0)، بساط جمناستك، لوحة بداية

الكترونية لحساب الزمن من البدء والنهاية.

مواصفات الأداء: يقف المختبر عند خط بداية الاختبار قرب حساس الانطلاق (يضغط على لوحة خاصة بالبدء) حيث يتم العد بالوقت عند الضغط على اللوحة وفي تللك اللحظة يستدير خلف الثاخص الاول ثم يواجه المانع الاول للقفز ؛ليجد حالة التحكم بأجزاء الجسم في الهواء وبعد ذلك يستدير من جانب شاخص المنتصف فيواجه المانع المرتفع فيغطس من اسفله؛ ليجسد حالة المرونة في أجزاء الجسم المختلفة وكذلك يبين المروق من المانع بعد ذلك يلتف من حول الثاخص الثالث فيواجه البساط فيقوم بعمل دحرجه امامية؛ ليجسد حال المرونة في مفاصل الاطراف العليا والسفلى وكذلك يبين حالة التوافق من خلال الحركات المختلفة في أداء الاختبار وثم يستمر بالحركة للالتفاف حول الثاخص الرابع ليواجه المانع المرتفع فيغطس من اسفله؛ لتجسيد حالة ثنات الاداء وابتعاده عن العشوائية والصدفة التي تخدم الانجاز في الاداء، بعد ذلك بستدير من جانب شاخص المنتصف فيواجه مانع القفز فيؤدي عملية القفز من فوقه كما فعل في الحاجز الاول؛ وذللك لإتاحة سبطرة المختبر على أنهاء الاختبار بانسيابية عالية، فضلا عن الخروج عن حالة التكرار المتوقع لترتيب أدوات ظروف الاختبار فيلتق حول الثناخص الخامس والانطلاق بأسرع ما يمكن الى النهاية والضغط على الحساس وبذللك يتوقف الوقت وفي هذه الحالة ينتهي الاختبار ومعرفة الوقت لكل مختبر . التسجيل: يقوم المُخنَّر بأداء محاولة واحدة فقط ويتم تسجيل الزمن لها حيث كلما كان زمن الاختبار أقل كلما كانت درجة المُخنَبر هي الافضل والعكس بالعكس. 
مجلة كلية التربية الرياضية - جامعة بغداد * المجلا التاسع والعشرون ** العدد الثاني * لسنة

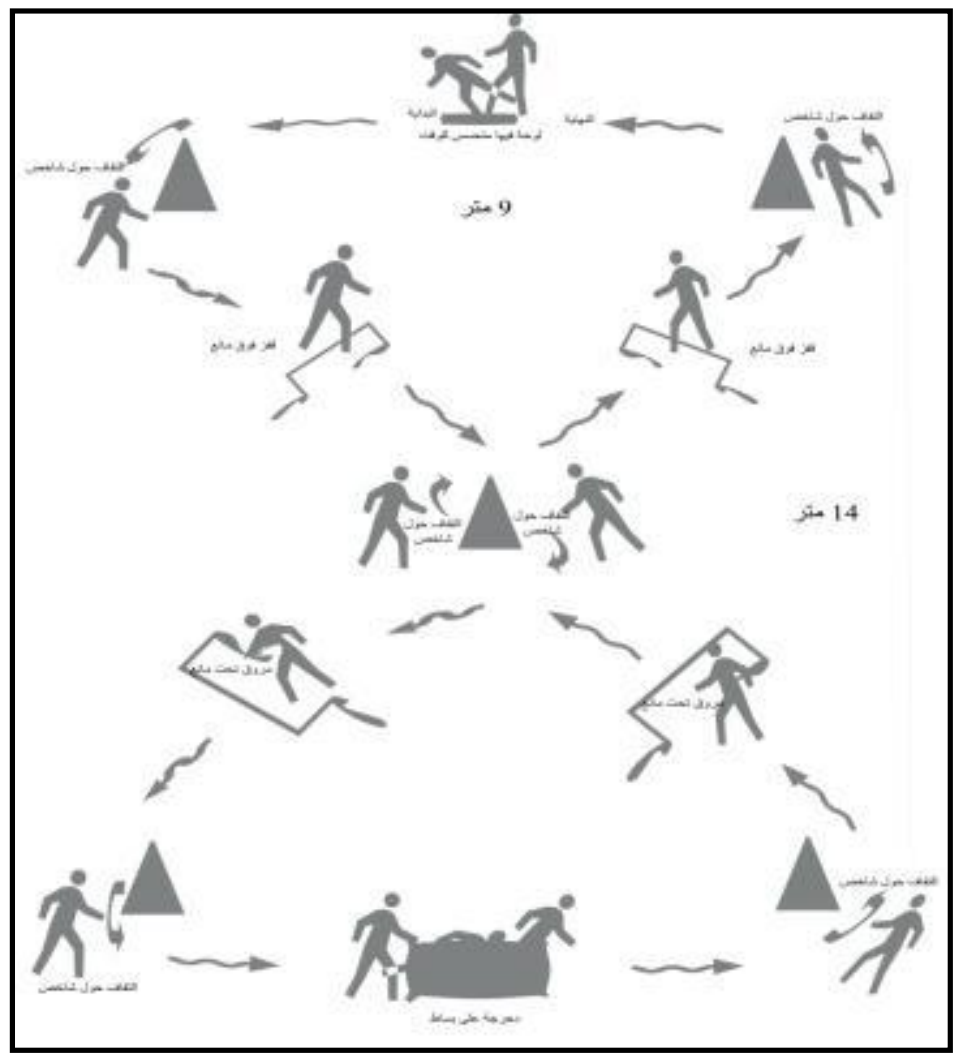

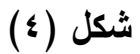

يوضح اختبار (الرشاقة)

Y -

•الهدف من الاختبار : قياس القدرة على الاستجابة والتحرك بسرعة ودقة على وفق الاختبار والمثير • • الأدوات: منطقة فضاء مستوية خالية من العوائق بطول (•r) متر وبعرض (r) مثر، شريط قياس، ساعة

الإجراعات: نخطط منطقة الاختبار بثلاثة خطوط المسافة بين كل خط وأخر ( • ع, 7)متر وطول( (1) منر . مواصفات الأداء: يقف المختبر عند إحدى نهايتي خط المنتصف في مواجهة الحكم الذي يقف عند نهاية الطرف الاخر للخط، يتخذ وضع الاستعداد إذ يكون خط المنتصف بين القدمين والجسم ينحني للأمام قليلاً، يمسك الحكم بساعة الإيقاف بإحدى يديه ويرفعها الى الأعلى، ثم يقوم بسرعة بتحريك ذراعة أما بناحية اليسار أو اليمين وفي الوقت نفسه يقوم بتتغيل الساعة، يستجيب المختبر لإثارة اليد ويحاول الركض بأقصى سرعة ممكنة في الاتجاه المحدد للوصول الى خط الجانب الذي يبعد عن خط المنتصف (•ع,7)م، عندما يقطع المختبر خط الجانب الصحيح يقوم الحكم بإيقاف الساعة وبالعكس حتى الوصول الى الاتجاه الصحيح وانتهاء الجانب الصحيح، يعطى المختبر عشر محاولات منتالية بين محاولة وأخرى (•ـ) ثانية وبواقع خمس محاولات لكل جانب، يتم اختبار كل جانب بطريقة عشوائية متعاقبة. 
مجلة كلية التربية الرياضية ـ جامعة بغداد * المجلد التاسع والعشرون * العدد الثاني ** لسنة

• التسجيل: يقوم بإدارة الاختبار (المسجل) الذي يقوم بالسحب العشوائي للكروت وكتابة نرتيب المحاولات العشر على بطاقة كل مختبر على حدة، و (المحكم) يقوم بالنداء على المختبر وإعطاء الإثارة للبدء لكل محاولة وحساب الزمن في بطاقة المختبر •

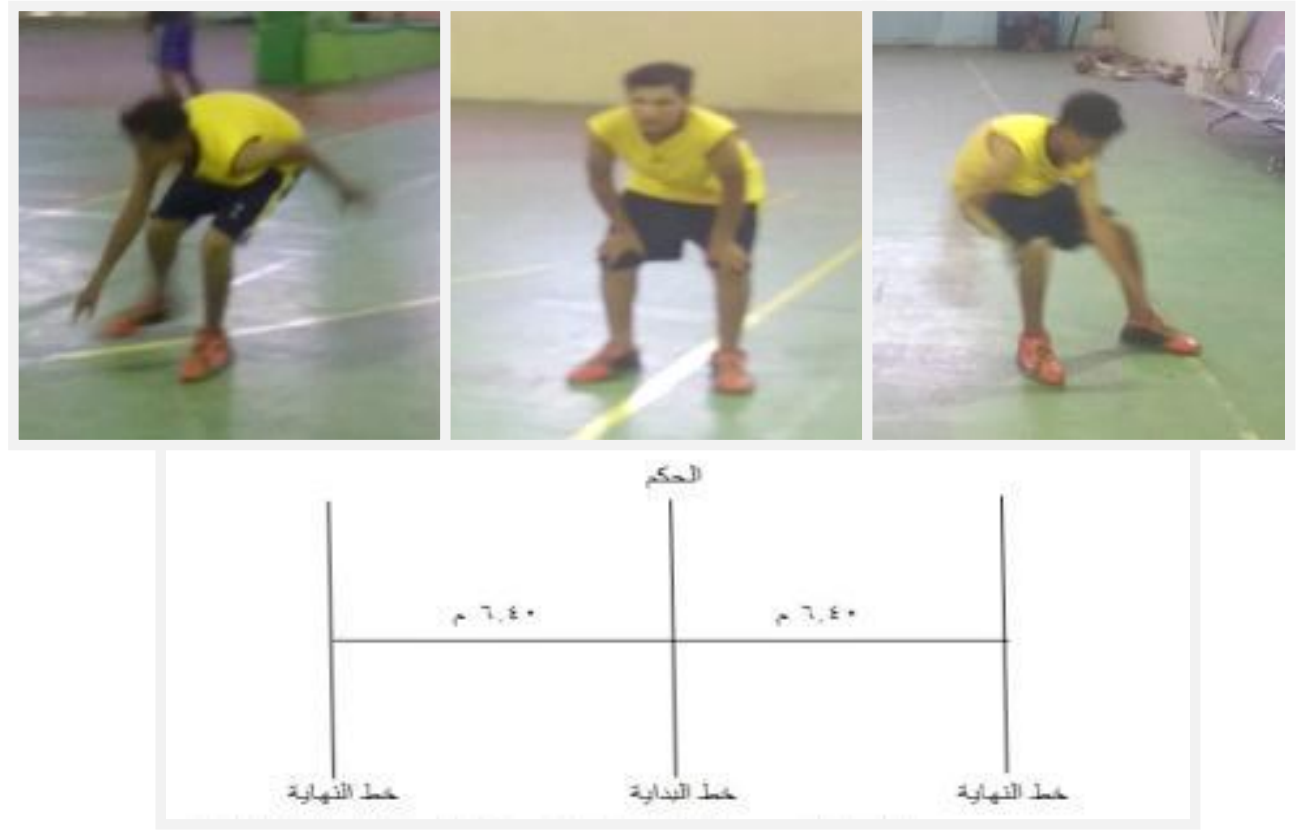

شكل (•)

يوضح اختبار نيلسون للاستجابة الحركية الانتقائية

r- r- r التجرية الاستطلاعية:

أن التجربة الاستطلاعية مهمة للباحثين لغرض التعرف على المعوقات والصعوبات التي من المحتمل

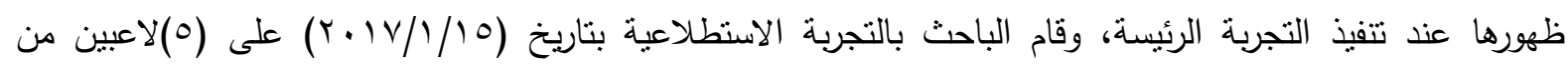
مجتمع البحث الأصلي، إذ كان الهدف من التجربة ما يأني: • التعرف على مدى تقهم اللاعبين واستيعابهم لمفردات التمرينات الخاصة من حيث ربط الحبال المطاطية بأجزاء الجسم المحددة لكل مجموعة التي تشتخدم هذه الوسيلة. • التأكد من صلاحية الأدوات والأجهزة التي سيتم استعمالها في التجربة الرئيسة وخصوصاً الحبال المطاطية وصلاحيتها من حيث انتهاء الددة الخاصة لمرونتها الواقعية والتأكد من التاريخ لنفاذ صلاحيتها وأبدال التالفة منها بعد هذه التجربة. • • التعرف على الصعوبات والمشكلات التي قد نواجه الباحث عند إجراء التمرينات والاختبارات لغرض تجاوزها. • معرفة عدد أفراد فريق العمل المساعد الذي سيحتاجه البحث عند إجرائه الاختبارات وكذلك تدريبهم على طريقة التسجيل. • التعرف على الوقت المستغرق في تتفيذ الاختبارات. 


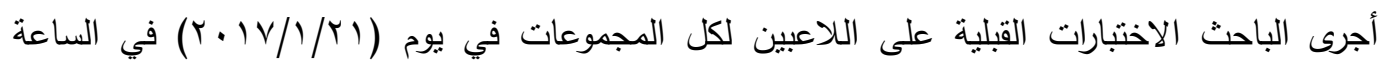

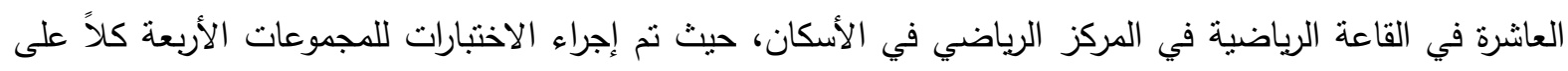

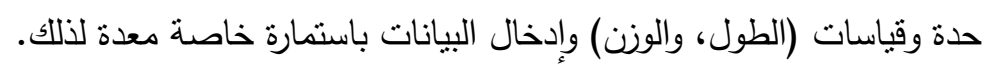

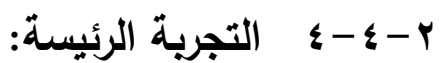

قام الباحث بوضع وربط الحبال للمجموعات الثلاثة التي تستخمها ما عدى المجموعة (الضابطة) التي لتي

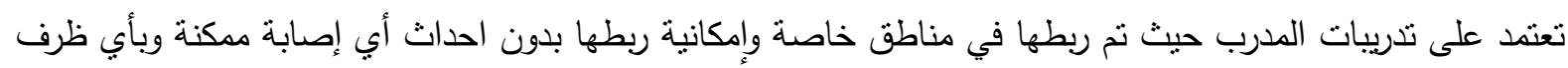

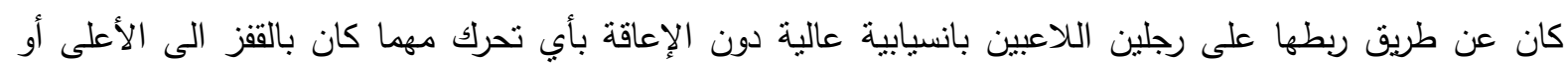
التحرك للجانبين (اليمين، واليسار) والاستفادة من التجربة الاستطلاعية لذلك، وكذلك ربطها في اليد من خلال قفازات تم

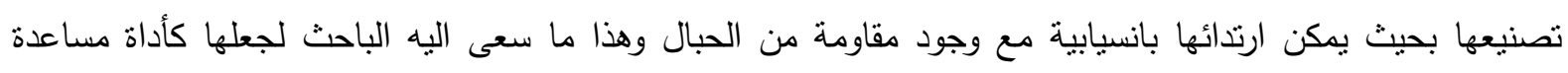
جديدة لقبضة اليد لفائدتها الكبيرة في تتطيط الكرة والمناولة والتصويب والمراوغة والخداع..... الخخ، وكذلك الذراعين وكيفية ربطها بصورة تسمح بأداء جميع التمرينات بشكل سلس مع وجود مقاومة وهي التي يهدف الباحث لجطأها كأداة مساعدة

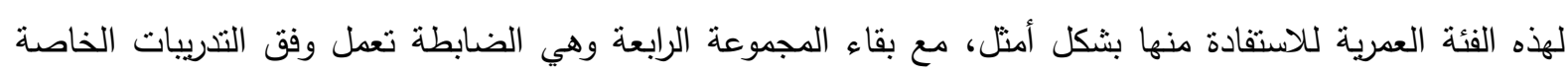
بالمنهاج المعد من المدرب، ومدة التدريب بهذه بأدوات مساعدة لفترة (^) أسابيع وبواقع (؟r) وحدات (تدريبية) أسبوعياً

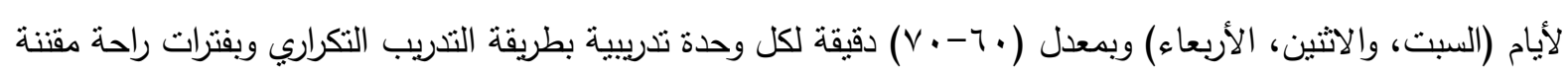

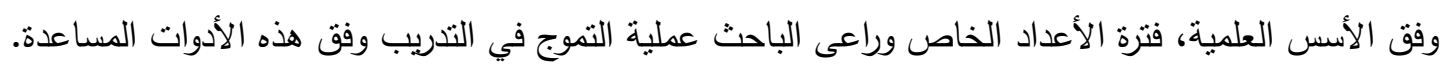

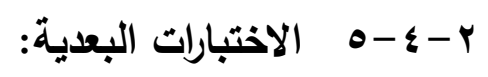

بعد الانتهاء من المنهاج المعد أجرى الباحث الاختبارات البعدية على اللاعبين لكلى المجموعات في يوم

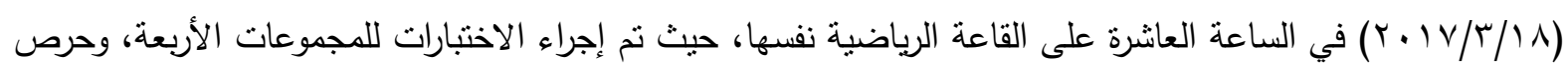
الباحث على توفير الإجراءات والثروط نفسها التي كانت في الاختبارات القبلية.

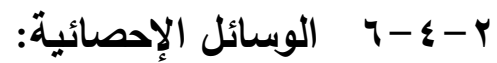

بعد جمع البيانات قيد الدراسة استخدم الباحث الوسائل الإحصائية التي تلائم أهداف البحث بواسطة الحقيبة

$$
\text { الإحصائية (SPSS) إصدار (Yr). }
$$


مجلة كلية التربية الرياضية - جامعة بغداد * المجلد التاسع والعثرون ** العدد الثاني ** لسنة

r- المبحث الثالث: عرض وتحليل ومناقشة النتائج:

r-

جدول (r) (1) (1)

يبين الأوساط الحسابية والانحرافات المعيارية وقيمة (ت) المحسوية بين الاختبارات القبلية والبعدية للمجموعات الأربعة

\begin{tabular}{|c|c|c|c|c|c|c|c|}
\hline \multirow{2}{*}{ الفروق دلالة } & \multirow{2}{*}{ قيمة (ت) } & \multicolumn{2}{|c|}{ الاختبارات البعدية } & \multicolumn{2}{|c|}{ الاختبارات القبلية } & \multirow{2}{*}{ الاختبارات } & \multirow{2}{*}{ المجموعات } \\
\hline & & $\varepsilon^{ \pm}$ & 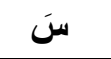 & $\varepsilon^{ \pm}$ & سنَ & & \\
\hline معنوي & $\varepsilon, \cdots$ & $r, \wedge \leqslant \vee$ & ro, s. & $\varepsilon, \cdot r V$ & $r \varepsilon, \tau$. & قوة قبضة (يمين) & $\overline{3}$ \\
\hline معنوي & r, & $\varepsilon, \cdots$ & $r v, \ldots$ & $\varepsilon, O Y V$ & rq, .. & قوة قبضة (بسار ) & . \\
\hline عشوائي & $1,9 \vee 9$ & $\cdot, 9 \curlyvee 9$ & A, rYo & 1,112 & 7,963 & 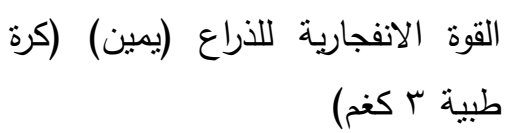 & 䇾 \\
\hline عشوائي & $r, 1 \cdot 1$ & $\cdot, \wedge 99$ & $1,1 \cdot 1$ & 1,215 & 7,793 & 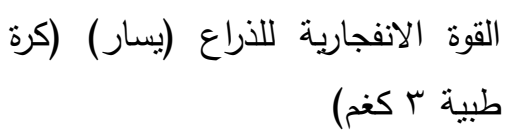 & $\widehat{\bar{\lambda}}$ \\
\hline عشوائي & $1,9 \wedge r$ & $Y, \wedge \leq 1$ & 19,人 & 3,709 & 18,64 & 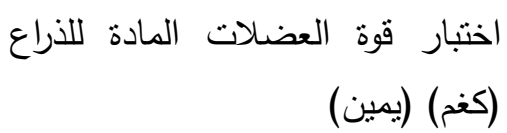 & $\overline{7}$ \\
\hline عشوائي & 1,990 & $r, 9 Y_{1}$ & $1 \wedge, \vee 7$ & 3,416 & 17,51 & 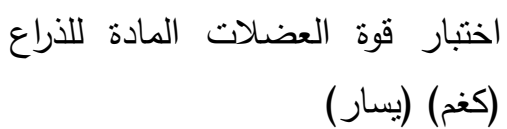 & 势 \\
\hline معنوي & $\varepsilon, 0 \leqslant r$ & $7, \Gamma \leq 1$ & $0 ., 70$ & $v, 11 r$ & $\{0,97$ & القزز العمودي من الثبات & \\
\hline معنوي & $0, r M r$ &., $0 Y q$ & $1 \cdot, \wedge \vee$ & $\cdot, V Y)$ & $V, r \cdot T$ & القوة المميزة بالسرعة للرجلين & \\
\hline معنوي & $7, \Gamma \wedge q$ & $\cdot, \Sigma \vee \wedge$ & $1 \varepsilon, 11$ & $\cdot, \wedge 99$ & $|7, \varepsilon|$ & 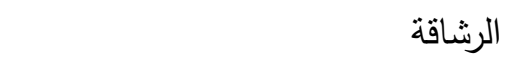 & \\
\hline معنوي & $0, \Gamma 9 \wedge$ & (1) & 1, & $\cdot, 1 \wedge \vee$ & Y,M & الاستجابة الحركية الانتقائية & \\
\hline
\end{tabular}


مجلة كلية التربية الرياضية - جامعة بغداد * المجلا التاسع والعشرون * العدد الثاني * لسنة

\begin{tabular}{|c|c|c|c|c|c|c|c|}
\hline الفروق & قالمحسة (ت) & \multicolumn{2}{|c|}{ الاختبارات البعدية } & \multicolumn{2}{|c|}{ الاختبارات القبلية } & الاختبارات & المجموعات \\
\hline معنوي & T,OTY & $r, O V V$ & $\Gamma_{0,7 .}$ & r,VAI & rr, $\varepsilon$. & قوة قبضة (يمين) & \\
\hline معنوي & $\varepsilon, \varepsilon \vee Y$ & $\varepsilon, \cdot r \varepsilon$ & ro,r. & $\varepsilon, 979$ & . & قوة قبضة (بسار ) & $y^{y^{\prime}}$ \\
\hline معنوي & $r, 071$ & $1, r \cdot 0$ & $\Lambda, 9 \leqslant 0$ & 1,203 & 8,002 & كغم) (يمين) القوة الانفجارية للذراعين(كرة طبية ب & 可 \\
\hline معنوي & $r, r \vee T$ & $1, r q \wedge$ & $\wedge, \vee 9 \wedge$ & 1,320 & 7,997 & 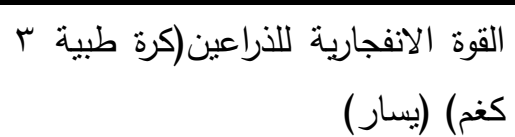 & $\equiv$ \\
\hline معنوي & $r, \varepsilon \wedge \Lambda$ & 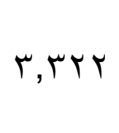 & $r \cdot, 11$ & 3,618 & 18,74 & (خغن) (يمين) قوة العضلات المادة للذراع & $\bar{g}$ \\
\hline معنوي & Ү,१८५ & $r, 01 Y$ & 19,71 & 3,311 & 17,89 & (ختبار قوة العضلات المادة للذراع & 弗 \\
\hline عشوائي & $r, 111$ & $7, V \cdot 1$ & $\varepsilon V, I T$ & $\wedge, 1 \ldots$ & $\leqslant 0, \vee_{0}$ & الققز العمودي من الثبات & \\
\hline عشوائي & $1,9 \vee r$ & מדו, & $\wedge, \varepsilon)$. & .,ATl & $V, M_{\Lambda}$ & القوة المميزة بالسرعة للرجلين & \\
\hline عشوائي & $r, \cdot 1 T$ & $\cdot, \vee \leqslant 9$ & $1 \leqslant, 10$ & $\cdot, \wedge 70$ & 10,91 & الرشاقة & \\
\hline عشوائي & $1, \wedge 94$ & $\cdot, 10 \leqslant$ & 1,911 &., 197 & $Y, Y Y_{I}$ & الاستجابة الحركية الانتقائية & \\
\hline معنوي & $\wedge, q \leq \leqslant$ & r & $r \vee, \Lambda$. & ґ,^৭^ & . & قوة قبضة (يمين) & $\bar{z}$ \\
\hline معنوي & $0,1 \times 1$ & $r, r \cdot q$ & ґА, & $\varepsilon, \wedge Y l$ & $\Gamma \varepsilon, \wedge)$ & قوة قبضة (يسار ) & $\frac{y^{\prime}}{y^{\prime}}$ \\
\hline معنوي & $\varepsilon, 111$ & $1, \Sigma \Lambda_{\Lambda}$ & $9, r \mu$. & 1,323 & 8,115 & كغة) (يمين) الانفجارية للذراعين (كرة طبية r & a! \\
\hline معنوي & $0, \ldots 1$ & 1,011 & $\wedge, 99 \wedge$ & 1,428 & 7,895 & 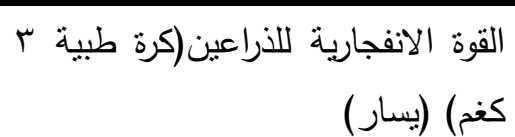 & $\widehat{\cong}$ \\
\hline معنوي & 7,811 & $\varepsilon, 1 Y V$ & r & 3,712 & 18,99 & 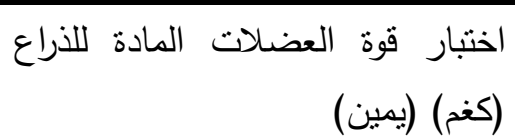 & $\overline{7}$ \\
\hline معنوي & r, , Vo & $r, \vee \backslash \uparrow$ & $r \cdot, 09$ & 3,411 & 18,43 & 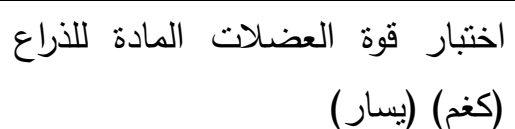 & $\begin{array}{l}\text { 习े. } \\
\text { ने }\end{array}$ \\
\hline معنوي & $\vee, 1 \ldots$ & 7,991 & $01, V \wedge$ & $\vee, 74$. & $\leq 0, \pi T$ & القفز العمودي من الثبات & q. \\
\hline معنوي & $\varepsilon, \vee १ \uparrow$ &., $97 \leqslant$ & $9,91 \%$ & $\cdot, 9 Y 7$ & $v, \varepsilon 11$ & القوة المميزة بالسرعة للرجلين & $\nexists$ \\
\hline معنوي & 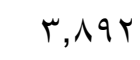 & $\cdot, \wedge \leq r$ & س & $\cdot, \wedge \wedge 0$ & $10, \mathrm{VA}$ & الرشاقة & $\lambda$ \\
\hline معنوي & 0,111 & $\cdot, 1 \vee 9$ & $1,7 T_{1}$ &., $10 \leqslant$ & $r, r_{\Lambda}$ & الاستجابة الحركية الانتقائية & $\because 9$ \\
\hline
\end{tabular}


مجلة كلية التربية الرياضية - جامعة بغداد * المجلد التاسع والعثرون * العدد الثاني ** لسنة

\begin{tabular}{|c|c|c|c|c|c|c|c|}
\hline الفروقة & قيمة (ت) & \multicolumn{2}{|c|}{ الاختبارات البعدية } & \multicolumn{2}{|c|}{ الاختبارات القبلية } & الاختبارات & المجموعات \\
\hline معنوي & $0, \vee 10$ & $r, \tau \leq \tau$ & $r \varepsilon, \varepsilon$. & $\varepsilon, \cdots$ & $r r, \ldots$ & قوة قبضة (يمين) & $\overline{\bar{y}}$ \\
\hline معنوي & $\varepsilon, \ldots$ & $\varepsilon, 07$. & ro, 7 . & $\varepsilon, \lambda \backslash 7$ & $\Gamma \varepsilon, \wedge$. & قوة قبضة (يسار ) & $\frac{y^{2}}{3}$ \\
\hline معنوي & $r, \wedge r q$ & $\cdot, 9 \wedge 9$ & $\Lambda, 9 / r$ & 1,221 & 7,822 & كغم) (يمين) القوة الانفجارية للذراعين (كرة طبية r & $\overrightarrow{7}$ \\
\hline عشوائي & $r, I Y r$ & $\cdot, 9 Y r$ & $\wedge, \cdots$ & 1,415 & $V, 790$ & 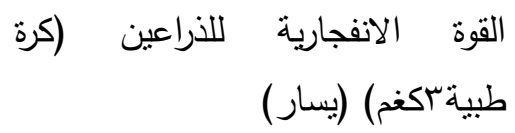 & \\
\hline معنوي & $r, \varepsilon \leq q$ & $r, V \leqslant 1$ & $r \cdot, 7 \Lambda$ & 3,661 & 18,59 & (خغت) (يمين) & \\
\hline عشوائي & $1,9 \wedge 1$ & $r, Y ו 1$ & $1 \wedge, 74$ & 3,511 & 17,73 & اختبار قوة العضلات المادة للذراع & \\
\hline معنوي & $r, \varepsilon \varepsilon r$ & $7,00 \leqslant$ & $0 ., 91$ & $v, \ldots r$ & $\varepsilon\rceil, \wedge \vee$ & الققز العمودي من الثبات & \\
\hline معنوي & $V, r)$ & $\cdot, T \vee \wedge$ & $\wedge, 99 \vee$ & $\cdot, \wedge \wedge \mu$ & $v, r \mu q$ & القوة المميزة بالسرعة للرجلين & \\
\hline معنوي & $7, \wedge \cdot 1$ & $\cdot, 0 \leqslant 1$ & $1 \varepsilon, \cdot 1$ & $\cdot, \wedge \vee \top$ & 17,01 & الرشاقة & \\
\hline معنوي & $\wedge, 1 \cdot 1$ & $\cdot, 10 \leqslant$ & $1, \wedge \vee Y$ & $\cdot, I V T$ & $r, \varepsilon \cdot 1$ & الاستجابة الحركية الانتقائية & \\
\hline
\end{tabular}

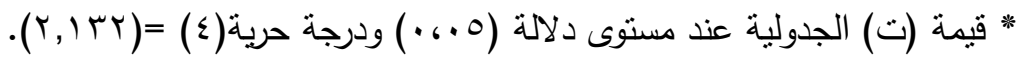

من خلال الجدول (r) أظهرت النتائج ان قيمة (ت) المحسوبة لمتغيرات المجموعات الأربعة (التجريبية الأولى، والتجريبية الثانية، والتجريبية الثالثة، والضابطة) بالاختبارات القبلية والبعدية هي أكبر من قيمتها الجدولية عند مستوى دلالة (0., •) ودرجة حرية (ع) مما يدل على معنوية الفروق في هذه المجموعات ولصالح الاختبارات البعدية وذللك للدور الكبير للتمرينات المستخدمة بالحبال المطاطية مما أثز إيجابياً على بعض القدرات البدنية للاعبي كرة السلة وهذا يحقق الغرض من الدراسة، ما عدا بعض المتغيرات في المجموعة التجريبية الأولى (القوة الانفجارية للذراعين) كرة طبية) (يمين، ويسار)، اختبار قوة العضلات المادة للذراع (يمين، ويسار)، والمجموعة التجريبية الثانية (القفز العمودي، والقوة المميزة بالسرعة، والرشاقة، والاستجابة الحركية)، والمجموعة الضابطة (القوة الاففارية للذراعين(كرة طبية) (بسار)، اختبار قوة العضلات المادة لذراع (يسار) كانت القيمة المحسوبة أقل من القيمة الجدولية، مما يدل على عثوائية الفروق بالرغم من أن هناك نطور نسبي للتمرينات المعدة بالحبال المطاطية وكذلك المعدة من المدرب وهذا يظهر من خلا الأوساط الحسابية. 
مجلة كلية التربية الرياضية - جامعة بغداد * المجلا التاسع والعشرون * العدد الثاني * لسنة

r-r عرض نتائج الاختبارات البعدية بين المجموعات الأريعة وتحليلها:

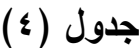

يبين الأوساط الحسابية والانحرافات المعيارية وقيمة (ف) المحسوية والجدولية بين

الاختبارات البعدية للمجموعات الأربعة

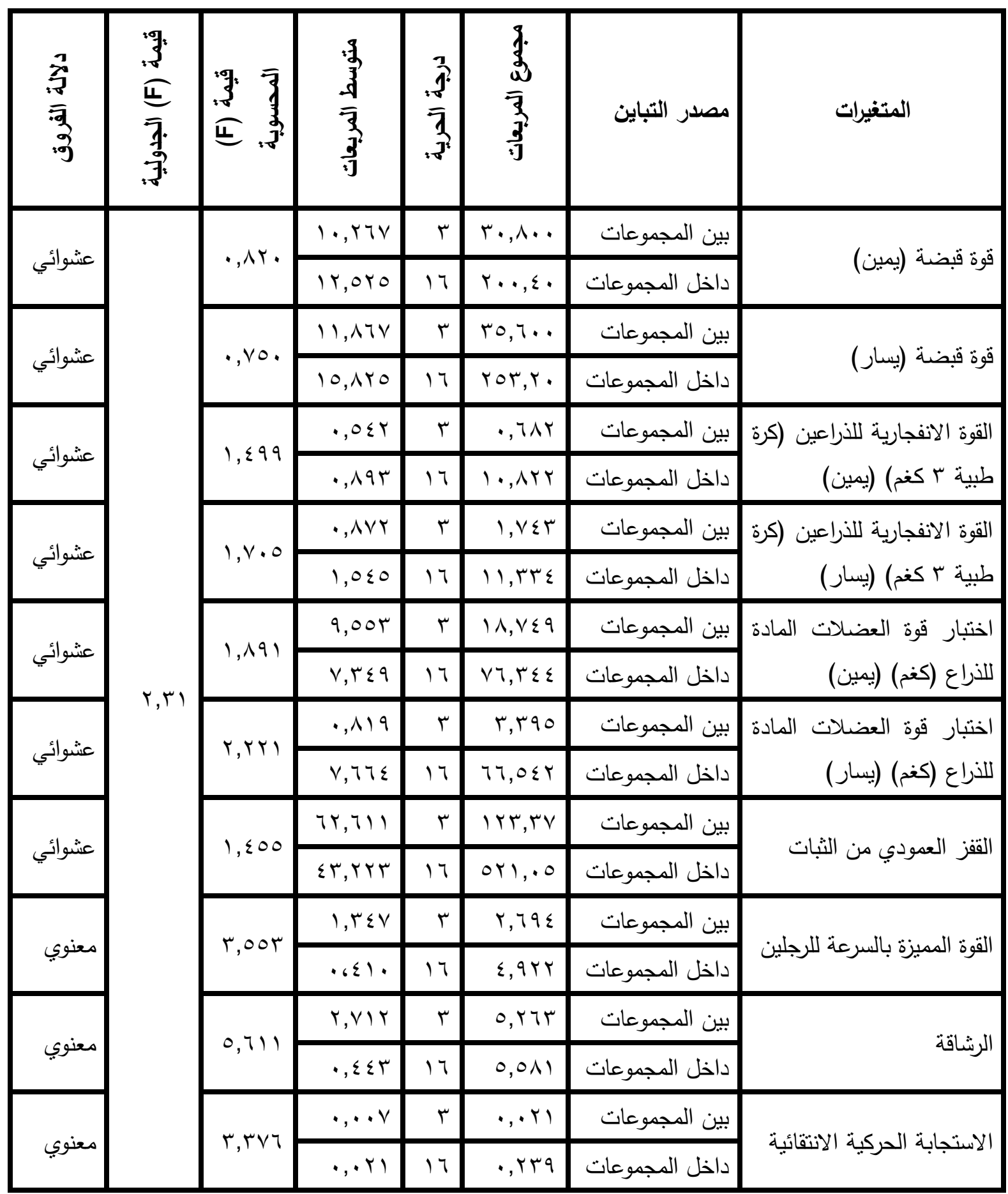

* عند مستوى دلالة(0* . • ) ودرجة حرية (r-7 ( ). 
مجلة كلية التربية الرياضية - جامعة بغداد * المجلا التاسع والعشرون * العدد الثاني * لسنة

من خلال الجدول (乏) أظهرت النتائج ان قيمة (ف) المحسوبة بين متغيرات المجموعات الأربعة (التجريبية الأولى، والتجريبية الثانية، والتجريبية الثالثة، والضابطة) بالاختبارات البعدية لـ (القوة المميزة بالسرعة، والرشاقة، والاستجابة الحركية) هي أكبر من قيمتها الجدولية عند مستوى دلالة (0. . •) ودرجة حرية (r-7 (1) مما يدل على معنوية الفروق في هذه المجموعات ولصالح الاختبارات البعدية وذلك للاور الكبير للتمرينات المستخدمة بالحبال المطاطية مما أثر إيجابياً على بعض القدرات البدنية للاعبي كرة السلة وهذا يحقق الغرض من الدراسة، وعشوائيتها في المتغيرات الأخرى بالرغم من التطور الحاصل لها في الاختبارات البعدية من الجدول (r).

جدول (•)

يبين قيمة أقل فرق معنوي (L.S.D) للمجموعات الأريعة لاختبار القوة المميزة بالسرعة للرجلين

\begin{tabular}{|c|c|c|c|}
\hline دلالة الفروق & مستوى الدلالة & فرق الأوساط & الاختبارات \\
\hline معنوي & .6. & r, ¿૫.** & $r^{b}-I$ \\
\hline عشوائي & .6 .74 & $\cdot, 901$ & p \\
\hline معنوي & $\cdot, .11$ & $1, \wedge \vee r^{*}$ & م' - م ض \\
\hline معنوي & $\cdot, \cdot \leq 7$ & $1,0, r *-$ & $r^{b}-r$ \\
\hline عشوائي & $\cdot, 1 \leqslant r$ & $\cdot, 0 \wedge \vee-$ & مr - م ض \\
\hline عشوائي & .611. & $\cdot, 910$ & مץ - م ض \\
\hline
\end{tabular}

من الجدول (0) أظهرت النتائج بين للمجموعات الأربعة لاختبار القوة المميزة بالسرعة للرجلين لأقل فرق

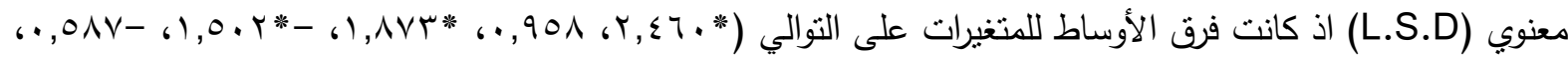
ه (9, •)، وكانت معنوية عند مسنوى دلالة (0.، •) بين المجموعة الأولى والثانية، والأولى والضابطة، والثانية والثالثة ولصالح المجمعة الأولى والثالثة وعشوائيتها بين المجموعة (الأولى والثالثة) و (المجموعة الثانية والضابطة) و (الثالثة والضابطة) وكانت الأفضلية الى المجموعة الأولى ومن ثم الثالثة لاعتمادهما على الأداة المساعدة في الرجلين مما أدى الى تطور هذه القدرة. 
مجلة كلية التربية الرياضية - جامعة بغداد * المجلا التاسع والعثرون ** العدد الثاني ** لسنة

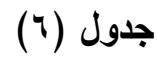

يبين قيمة أقل فرق معنوي (L.S.D) للمجموعات الأربعة لاختبار الرشاقة

\begin{tabular}{|c|c|c|c|}
\hline دلالة الفروق & مستوى الالالة & فرق الأوساط & الاختبارات \\
\hline معنوي & $\cdot 6 \cdot \leqslant 9$ & -,$\vee \varepsilon-*$ & $r^{5}-1^{5}$ \\
\hline معنوي & דr. & $\cdot, 7 \lambda^{*}$ & م' - مس \\
\hline عثوائي & $\cdot, \cdot \vee \wedge$ & $\cdot, 1 \ldots$ & م' - م ض \\
\hline معنوي & $\cdot, \cdot \leq V$ & $1, \leqslant \nvdash *$ & م \\
\hline معنوي & $\cdot, \cdots 7$ & $\cdot, \wedge \varepsilon \cdot *$ & مr - م ض \\
\hline عشوائي & . & $\cdot, 0 \wedge-$ & مץ" - م ض \\
\hline
\end{tabular}

من الجدول (T) أظهرت النتائج بين للمجموعات الأربعة لاختبار الرشاقة لأقل فرق معنوي (L.S.D) اذ

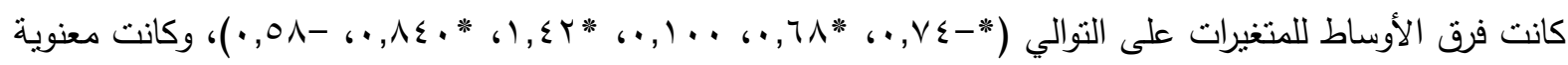
عند مستوى دلالة (0.، •) بين المجموعة الأولى والثانية، والأولى والثالثة، والثانية والثالثة، والثانية والضابطة، ولصالح المجموعة الثالثة والأولى ومن ثم الثانية وذلك لان القياس بالزمن وهو عكسي أي كلما قل هو الأفضل، وعشوائيتها بين المجموعة (الأولى والضابطة) و (المجموعة الثالثة والضابطة) وكانت الأفضلية الى المجموعة الثالثة ومن ثم الأولى وبعدها المجموعة الثانية لاعتمادهم على الأداة المساعدة مما أدى الى تطور الرشاقة لديهر.

\section{جدول (v)}

يبين قيمة أقل فرق معنوي (L.S.D) للمجموعات الأربعة لاختبار الاستجابة الحركية الانتقائية

\begin{tabular}{|c|c|c|c|}
\hline دلالة الفروق & مستوى الالالة & فرق الأوساط & الاختبارات \\
\hline معنوي & $.6 \cdot T r$ & $\cdot, \nvdash \vee q *-$ & p \\
\hline عشوائي & 7.6. & $\cdot, \cdot \wedge 9-$ & م \\
\hline معنوي & $\cdot, .11$ & $\cdot, Y \leq \cdot *$ & م' - م ض \\
\hline معنوي & דו & $\cdot, 19 . *$ & $r^{b}-r$ \\
\hline عشوائي & rוT, & & مr - م ض \\
\hline عشوائي & סT4 & $\cdot, 101-$ & مج" - م ض \\
\hline
\end{tabular}

من الجدول (V) أظهرت النتائج بين للمجموعات الأربعة لاختبار الاستجابة الحركية الانتقائية لأقل فرق

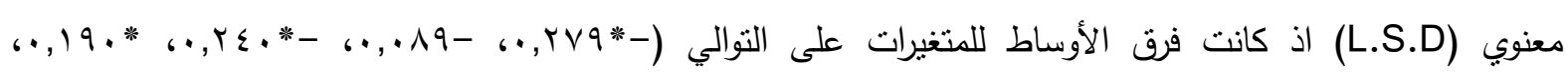
9 .,.•، - (10, •)، وكانت معنوية عند مستوى دلالة (0.، •) بين المجموعة الأولى والثانية، والأولى والضابطة، والثانية والثالثة، ولصالح المجموعة الأولى الثالثة وذلك لان القياس بالزمن وهو عكسي أي كلما قل هو الأفضل، 
مجلة كلية التربية الرياضية - جامعة بغداد * المجلد التاسع والعشرون * العدد الثاني * لسنة

وعشوائيتها بين المجموعة (الأولى والثالثة) و(الثانية والضابطة و(المجموعة الثالثة والضابطة) وكانت الأفضلية الى المجموعة الأولى ومن ثم الثالثة لاعتمادهما على الأداة المساعدة مما أدى الى تطور الاستجابة الحركية الانتقائية لديهم.

r-r r r مناقشة النتائج: ومن خلال النتائج التي تم التوصل إليها الباحث من الجدول (r) نلاحظ إن هناللك فروقاً في المجموعات الأربعة (التجريبية الأولى، والتجريبية الثانية، والتجريبية الثالثة، والضابطة) بين الاختبارات القبلية والبعدية وبعد مقارنة قيمة(ت) المحسوبة مع قيمنها الجدولية والتي أظهرت القيمة المحسوبة أكبر من القيمة الجدولية عند مستوى دلالة (0., •) ودرجة حرية (ع) مما يدل على معنوية الفروق ولصالح الاختبارات البعدية في أغلب المتغيرات للمجموعات التجريبية (الأولى، والثانية، والثالثة) التي استخدمت التمرينات الجديدة بالحبال المطاطية، مما يدل ان لهذه التمرينات الأثز الكبير والإيجابي في التطور الحاصل لهم ويعزو الباحث هذا التحسن الى استخدام التذريب بالحبال المطاطية والذي اظهر تقدماً واضحاً في هذه المتغيرات الذي كان له الأثر الايجابي في نطور المجاميع العضلية العاملة في الجسم بما يحقق الانسجام في مسارات الأداء الحركية المناسبة، وفي الجدول(r) أظهرت أغلب النتائج ان النظور الذي حصل للاختبارات للرجلين أكبر من الذراعين كون استعمال الأداة المساعدة في هذه المجموعة فقط للرجلين بالرغم من التطور البسيط للذراعين لاستمرار هذه المجموعة بالتدرب وفق منهاج يعتمد فيه بعض تمرينات الذراعين ذلك يؤكد في حالة وجود ضعف في العضلات العاملة للرجلين يتطلب من العاملين في مجال التدريب في كرة السلة استعمال هذه الوسيلة لما أظهرته من نتائج وأن مراعاة وضع هذه الوسائل التدريبية في الأجزاء والأماكن الصحيحة الأمر الذي ساعد على نطوير بعض القدرات البدنية بشكل كبير في هذا الجزء من الجسم اذ يؤكد Chad " أن الأوزان والمقاومات المضافة على كُلّ رجل والتي هي ضمن قابليات اللاعب، ستُقُّبي السيقانَ بشكل ملحوظ، بدون التخوف من خطرِ الإصابة في حركات

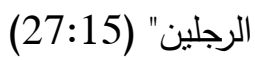

ويعزو الباحث أيضاً تطور بعض القدرات البدنية ذلك لفعالية استخدام هذه الأداة المساعدة الأمر الذي زاد من تأثير قوة الجاذبية الأرضية ومقاومات العضلات العاملة والتي هي العضلات (الفخذ، والساق، والكاحل) مما ادى الى تطويرها وزيادة مقاومتها لجذب الأرضي وهذا ما اكد اسماعيل "بان التدريب الموجة الى مجموعة معينة من العضلات يؤدي الى إحداث تطور فيها" (99:4).

وكذلك يتقق مع منصور العنبكي وآخرون "التدريبات اذا استخدمت بشكل علمي ومنظم فأنها تساهم وبشكل

كبير في تطوير القوة العضلية" (51:12).

وان لعبة كرة السلة بطبيعة أداء تمريناتها تعتمد على الارتقاء والقزز عالياً وكذلك ثي الرجلين والمحاورة بالكرة والخداع والتصويب والمراوغة والكثير من المهارات، وإذ يزيد من فعالية الحركة لدى اللاعبين مضافةً له الحبال المطاطية لما لها من خاصية المقاومة مع اتخاذ الثنكل الذي يتخذه الجسم من خلال الرجلين بدون اعاقتها ولكن تضيف 
مجلة كلية التربية الرياضية - جامعة بغداد ** المجلا التاسع والعشرون ** العدد الثاني ** لسنة

مقاومة تدريبية تظهر فائدتها بعد الانتهاء من المنهاج المعد لذلك، ساعد ذلك كثيراً في تطوير الحركة وأكد حسن ولبيب "ان ثتي الركبنتين والارتقاء مع حمل نقل أو مقاومات متغيرة معين تتمي القوة لعضلات الرجلين" (253:5).

وفي المجموعة التجريبية الثانية استعمل الباحث الأداة المساعدة على اليد والذراعين وقد أظهر الجدول (؟)

ان التطور الكبير حصل لهذه الأجزاء أكثر من الاختبارات التي تعتمد على الذراعين ذلك يتطلب من المدربين التركيز في تدريباتهم على هذه الأدوات المساعدة عند إيجاد ضعف باليدين والذراعين من أجل تحسين العضلات العاملة فيها وأكد محجوب "أذا أردت تطوير القوة استخدم تدريبات المقاومات" (126:13).

وفي المجموعة التجربيية الثالثة التي استعملت الأداة المساعدة بالحبال المطاطية لأجزاء الجسم (اليد، والذراعين، والرجلين) كان التطور أكبر في القدرات البدنية وهذا ما اظهره الجدول(ץ) مما يدل ان استعمال هذه الوسائل لفترة محددة اثثاء التدريبات لهذه الفئة العمرية (الناشئين) في بداية تدريباتهم تحسن وتطور لديهم القدرات البدنية بشكل مؤثر جداً وهذا ما يسعى اليه جميع العاملين في التدريب الرياضي وهو الاستخدام الأفضل من المجموعات الأخرى. وهذا يتفق مع ما اثنار اليه (أبو العلا عبد الفتاح) اذ "ترتبط السرعة بمستوى القوة العضلية وتناعد القوة على التغلب على مقاومة الاداء، كما نساعد على طول الخطوة" (188:1)، فضلا عن ذلك تطوير التوافق العصبي العضلي من خلال فاعلية تمارين الرشاقة، وهذا بتفق مع ما قاله (مفتي) اذ "كلما كان التوافق بين انقباض العضلات وارتخاءها متوافقاً أمكن تحقيق معدلات أفضل من السرعة" (205:10).

اما النطور الحاصل في القوة الانفجارية للذراعين والرجلين، فيعزو الباحث السبب الى فاعلية التدريب وباستخدام مقاومات مختلفة له الاثر في تطوير هذه القدرات "ان التمارين التي تستخدم فيها مقاومة كبيرة تعد من الأدوات المساعدة المناسبة لتطوير مكونات القوة الانفجارية" (113:11)، اذ ان تمارين القوة تزيد من قدرة العضلة على اثارة اكبر

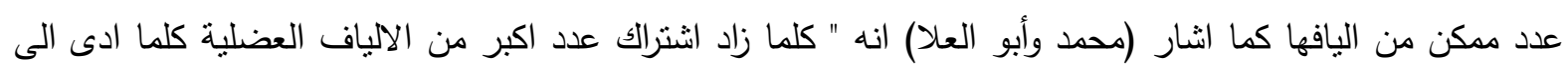
زيادة القوة التي تسنطيع العضلة انتاجها" (122:2)

والجدول (ع) يظهر لنا الفروق بين المجموعات الأربعة في المتغيرات المدروسة حيث أظهرت في اختبارات (قوة القبضة، والقوة الانفجارية للذراعين (يمين ويسار)، والعضلات المادة للذراعين (يمين وبسار) والقوة الانفجارية للرجلين) عشوائية الفروق ولكن عند ملاحظة الأوساط الحسابية لهذه الاختبارات الأربعة في الجدول (r) ان هناك تحسن ملحوظ بالرغم من انه لم يظهر احصائياً وجميع التطور في هذه الاختبارات كانت لصالح المجموعات التجريبية (الأولى، والثنانية، والتجريبية الثالثة) وكذلك للمجموعة الضابطة ولكن لهذه المجموعات الثلاثة كان النطور أكثر لما للتمرينات المستخدمة دور كبير وبارز في ذلك التطور، وفي الاختبارات (القوة المميزة بالسرعة، والرشاقة، الاستجابة الحركية الانتقائية) كان هناك فروق محسوسة بين المجموعات الأربعة وهذا ما أظهرته الجداول (0، ج، V) لأقل فرق معنوي (L.S.D) 
مجلة كلية التربية الرياضية - جامعة بغداد * المجلد التاسع والعشرون * العدد الثاني * لسنة

التطور الحاصل في صفة القوة المميزة بالسرعة للرجلين وكذلك الرشاقة والاستجابة الحركية يعود لتتمية المجموعات العضلية الرئيسة العاملة لحجم المقاومات المطلوب والتغلب عليها وهذا مع ما يراه (Behm) و (Sal) "ان نتمية سرعة الأداء يمكن أن يتم من خلال التمرينات التقليدية باستخدام المقاومات أذا ما استخدمت بسرعات كبيرة" (74:16).

وكذلك يؤكد النمر ونريمان "ان تدريبات الأثقال والمقاومات التي تهدف الى تتمية القوة العضلية تعمل على تحسين الأداء المهاري بما بمثل الحركات المستخدمة في التدريبات الأتقال سواء كانت مكائن او البارات أو الإطارات والتي عملت على تتمية القوة العضلية السريعة لأطراف بمسارات حركية مشابهة للأداء الفني" (44:7).

"ان تدريب القوة المميزة بالسرعة بطرائق تدريبية خاصة لامتلاك اللاعبين القوة والتردد السريع لتقلص

وانبساط العضلات في أثناء أداء التمرينات الخاصة" (59:3)

وان أغلب التمرينات التي استخدمها المدرب في منهاجه كان لها أثز ملحوظ في بعض الاختبارات ولكن أثزها نسبي مقارنتاً مع التمرينات في المنهاج الخاص بالمنقلات والحبال المطاطية، وهذا يحسب للمنهاج المعد من قبل المدرب في هذا التطور النسبي.

\section{ع - المبحث الرابع: الاستثتاجات والتوصيات. \\ ع - الاستتتاجات:}

ا. بأن تمرينات بالحبال المطاطية لها أثز إيجابي في تطوير بعض القدرات البدنية لاى ناشئي كرة السلة. r. أن الأفضلية في التمرينات كانت للمجموعات التجريبية الثلاثة التي تستعمل الحبال المطاطية في جميع الأجزاء (اليد، والذراعين، والرجلين)، وهناك تطور نسبي للمجموعة الضابطة.

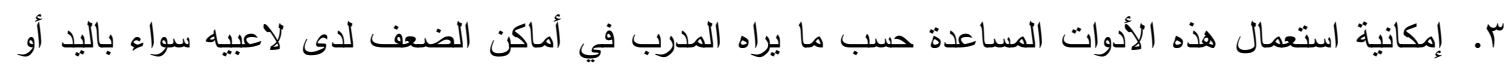
الذراعين او الرجلين لنقوية هذه الأجزاء بالثكل الذي يحسن من مستوى الأداء فيها وزيادة تحسن الأجزاء الأخرى. ـ. كان هناك نطور نسبي في بعض الاختبارات للمجموعة الضابطة وهذا يرجع للمنهج المعد من قبل المدرب له دور في هذا التطور •

ا. ضرورة التأكيد على استخدام التمرينات الحبال المطاطية لتطوير بعض القدرات البدنية لدى ناشئي كرة السلة. r. التأكيد على إجراء اختبارات دورية للاعبين النانشئين للتدريب والتعرف على أماكن الضعف لديهم واستخدام هذه الأدوات المساعدة وحسب تلاك المناطق لنطويرها بالثكل المناسب. r. تطوير المناهج التدريبية وشمول كل القدرات البدنية والحركية والمهارية والادراكية. 
مجلة كلية التربية الرياضية - جامعة بغداد * المجلا التاسع والعشرون * العدد الثاني * لسنة

ـ. إجراء بحوث ودراسات مشابهه على فئات عمرية وفعاليات أخرى.

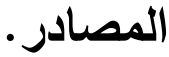

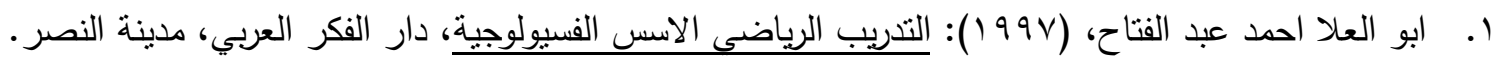
r. ابو العلا احمد وعبد الفتاح ومحمد حسن علاوي (997 (1): فسيولوجيا التدريب الرياضي، دار الفكر العربي،

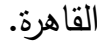

r. جميل قاسم محمد وأحمد خميس راضي(1) (1): موسوعة كرة اليد العالمية، طا، بغداد، مؤسسة الصفاء للمطبوعات.

ع. سعد محسن اسماعيل (1997 ()): تأثير أساليب تدريبية لنتمية القوة الانفجارية للرجلين والذارعين في دقة التصويب البعيد بالقفز عاليا في كرة اليد، أطروحة دكتوراه، كلية التربية الرياضية، جامعة بغداد. ه. سليمان علي حسن وعواطف محمد لبيب(997 (197): تتمية القوة العضلية، القاهر ، دار الفكر المعاصر.

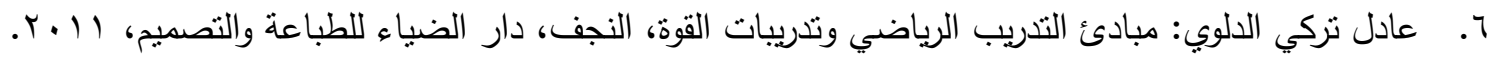
V. عبد العزيز النمر ونريمان الخطيب (997 (1): الأعداد البدنى والتدريبات الأثقال الناشئين في المرحلة ما قبل البلوغ، بغداد، مركز الكتاب للنشر.

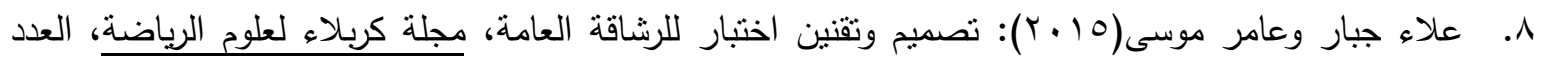

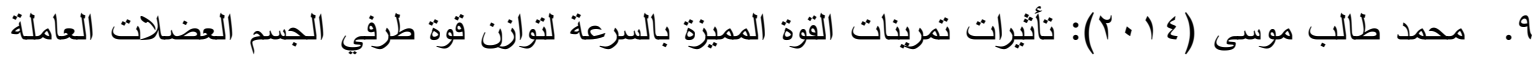
والمعاكسة في بعض الصفات البدنية الخاصة ومراحل انجاز عدوة . 1 م شباب، رسالة ماجستير، كلية التربية الرياضية القادسية.

• 1. مفتي ابراهيم حمادة (1 (. r): التدريب الرياضى الحديث تخطيط وتطبيق وقيادة، دار الفكر العربي، القاهرة. الـ منصور جميل العنبكي وقاسم حسن حسين (911 ()): اللياقة البدنية وطرق تحقيقها، مطبعة التعليم العالي، بغداد. ז ب. منصور جميل العنكي وآخرون(•199): الاسس النظرية والعلمية في رفع الأثقال، بغداد، دار الحكمة للطباعة

$$
\begin{aligned}
& \text { والنشر . } \\
& \text { rا (. وجية محجوب (997 (1)): علم الحركة، بغداد، بيت الحكمة. }
\end{aligned}
$$

ع ا. وديع ياسين وحسن محمد عبد العبيدي(999 ()): التطبيقات الاحصائية واستخدامات الحاسوب في بحوث التربية

$$
\text { الرياضية، الموصل، دار الكتب للطباعة والنشر . }
$$

15. Chad Waterbury(2005): MUSCLE REVOLUTION ,USA.

16. Behm and Sal D. Intended Rather than Actual movement velocity determines (1993) response journal of applied physiology.

17. Velocity specific training(2010) Experimenting with Everyday Science, Sports, U.S.A, Chelsea House books. Stephen M. 
مجلة كلية التربية الرياضية - جامعة بغداد * المجلا التاسع والعشرون * العدد الثاني * لسنة

ملحق (1)

يبين أسماء الخبراء والمختصين

\begin{tabular}{|c|c|c|c|}
\hline 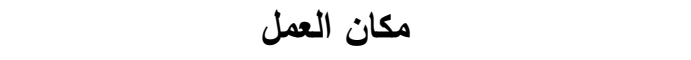 & التخصص & الاسم الثلاثي الثي & 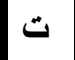 \\
\hline كلية التربية البدنية وعلوم الرياضة - جامعة القادسية & فسلجة - كرة سلة & أ.د فلاح حسن عبد الله & -1 \\
\hline كلية التربية البدنية وعلوم الرياضة - جامعة القادسية & الاختبارات والقياس & 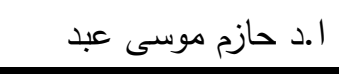 & $-r$ \\
\hline كلية التربية البدنية وعلوم الرياضة - جامعة القادسية & الاختبارات والقياس & أ. علاء جبار عبود & $-r$ \\
\hline كلية التربية البدنية وعلوم الرياضة - جامعة القادسية & ت تدريب - كرة سلة & ا.م.د رياض جمعة & $-\varepsilon$ \\
\hline كلية التربية البدنية وعلوم الرياضة - جامعة القادسية & تدريب - كرة يد & ا.م.د مشرق عزيز طنيش & -0 \\
\hline كلية التربية البدنية وعلوم الرياضة - جامعة القادسية & 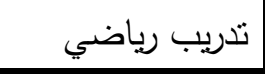 & أ.م عامر موسى عباس & $-v$ \\
\hline كلية التربية البدنية وعلوم الرياضة - جامعة القادسية & إدارة - كرة سلة & م.د فايز عبد السادة & $-\Lambda$ \\
\hline كلية التربية البدنية وعلوم الرياضة - جامعة القادسية & طرائق - كرة سلة & م.د ثامر حسين كحط & -9 \\
\hline
\end{tabular}

ملحق(r)

نموذج وحدة تدريبية للتمرينات باستعمال الحبال المطاطية

\begin{tabular}{|c|c|c|c|c|c|c|}
\hline 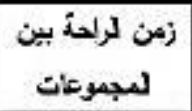 & بين لتمرينات لراحة & لمبسوعات & عد الثرل & همل الثُرين & ل لتمرينات & $ت$ \\
\hline 2 & 1 دفيقة & 3 & 5 نكرا & 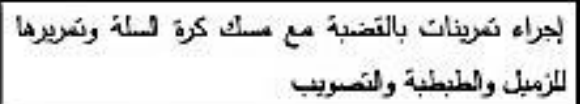 & ئوة للقبمنة & -1 \\
\hline 5-3 دمئة & 1 دفئة & 3 & 3 نكرال & 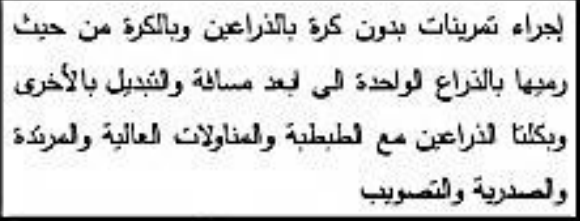 & لقوة: الآنجارية للنراعين & -2 \\
\hline 2 & 1 دنئة & 3 & 5 نكرال & 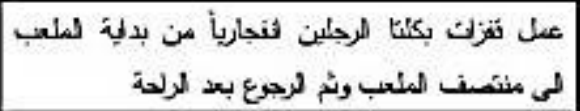 & لثوة الاثنجارية للرجلين & -3 \\
\hline 3-5 دتيّة & 1 دنيَّة & 3 & 3 نكرال & 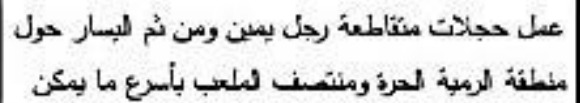 & لئوة العمبزة بالسرية للرجلين & -4 \\
\hline 3-3 دئية & 1 دفيَّة & 3 & 3 & 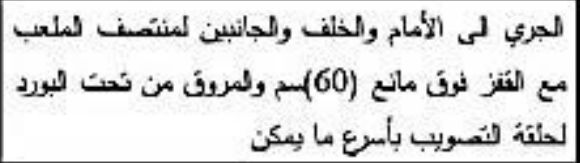 & لرئمائة & -5 \\
\hline 2 دنئة & 1 دنيَّة & 3 & 5 & 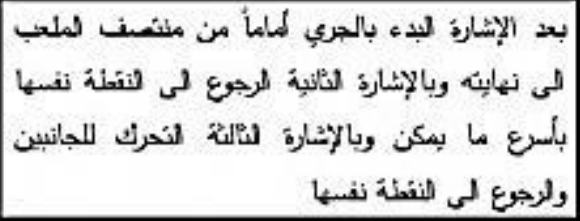 & الاستجابة الحركية & -6 \\
\hline
\end{tabular}

• إجراء الاحماء الخاص للذراعين والرجلين والتركيز على العضلات العاملة. 
مجلة كلية التربية الرياضية - جامعة بغداد * المجلا التاسع والعثرون ** العدد الثاني ** لسنة . I I

$$
\begin{aligned}
& \text { • تمطية العضلات وفق المدى الحركي المناسب تلافياً للإصابات. } \\
& \text { •وقت الوحدة التدريبية في الفترة المسائية من أيام التدريب. } \\
& \text { • بعد الانتهاء من فترة التدريب إجراء تمرينات التمطية لتهيئة العضلات العاملة والجسم ككل. }
\end{aligned}
$$
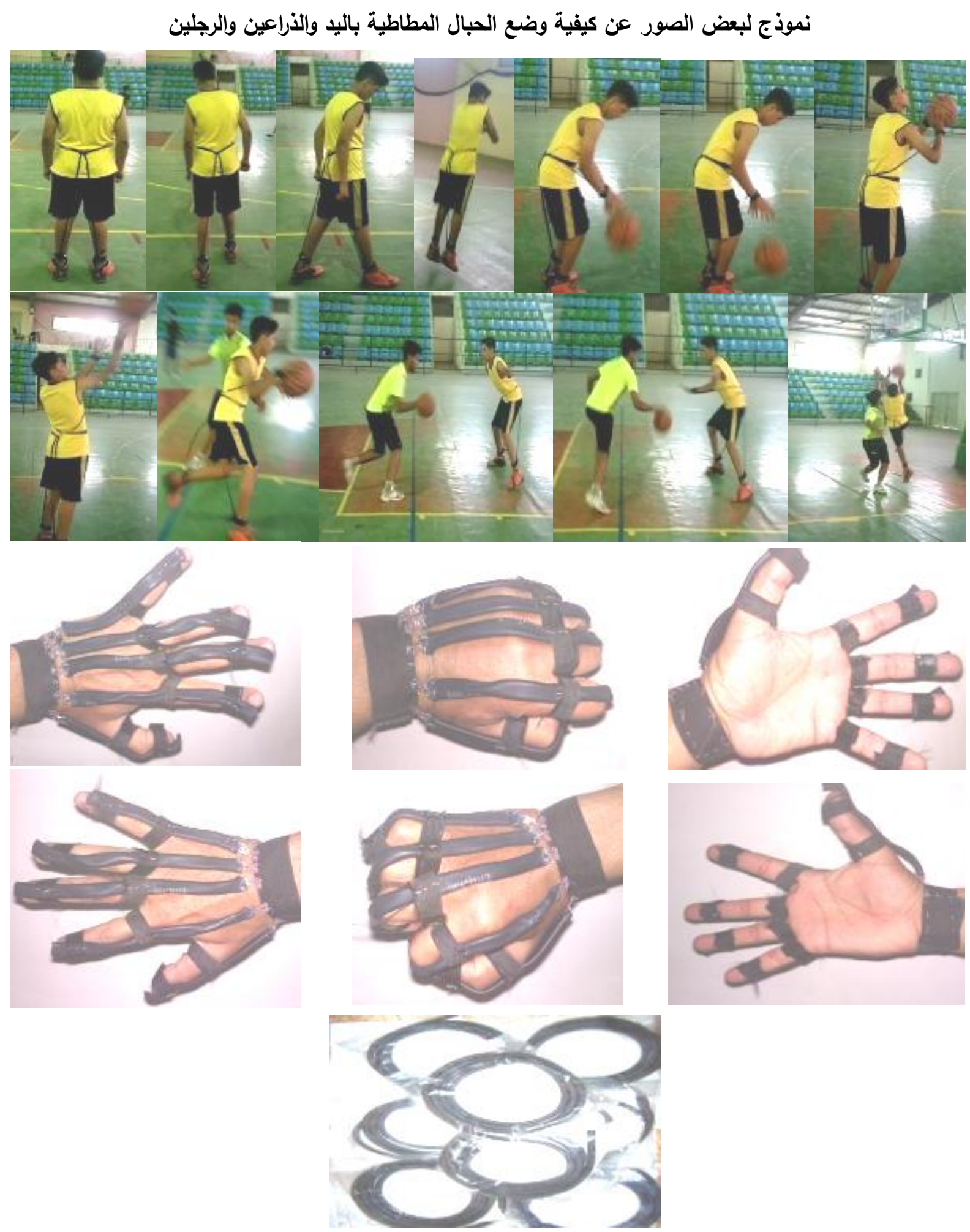